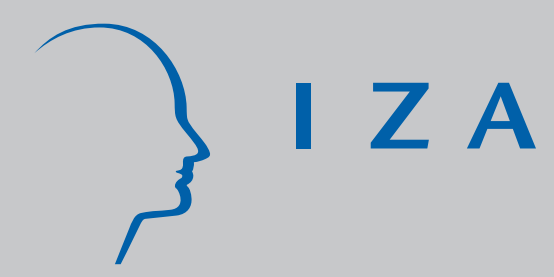

IZA DP No. 438

Employment Dynamics in the Romanian Labor Market: A Markov Chain Monte Carlo Approach

Alexandru Voicu

February 2002 


\title{
Employment Dynamics in the Romanian Labor Market: A Markov Chain Monte Carlo Approach
}

\author{
Alexandru Voicu \\ IZA, Bonn \\ Discussion Paper No. 438 \\ February 2002 \\ IZA \\ P.O. Box 7240 \\ D-53072 Bonn \\ Germany \\ Tel.: +49-228-3894-0 \\ Fax: +49-228-3894-210 \\ Email: iza@iza.org
}

This Discussion Paper is issued within the framework of IZA's research area Labor Markets in Transition Countries. Any opinions expressed here are those of the author(s) and not those of the institute. Research disseminated by IZA may include views on policy, but the institute itself takes no institutional policy positions.

The Institute for the Study of Labor (IZA) in Bonn is a local and virtual international research center and a place of communication between science, politics and business. IZA is an independent, nonprofit limited liability company (Gesellschaft mit beschränkter Haftung) supported by the Deutsche Post AG. The center is associated with the University of Bonn and offers a stimulating research environment through its research networks, research support, and visitors and doctoral programs. IZA engages in (i) original and internationally competitive research in all fields of labor economics, (ii) development of policy concepts, and (iii) dissemination of research results and concepts to the interested public. The current research program deals with (1) mobility and flexibility of labor, (2) internationalization of labor markets, (3) the welfare state and labor markets, (4) labor markets in transition countries, (5) the future of labor, (6) evaluation of labor market policies and projects and (7) general labor economics.

IZA Discussion Papers often represent preliminary work and are circulated to encourage discussion. Citation of such a paper should account for its provisional character. A revised version may be available on the IZA website (www.iza.org) or directly from the author. 
IZA Discussion Paper No. 438

February 2002

\section{ABSTRACT}

\section{Employment Dynamics in the Romanian Labor Market: A Markov Chain Monte Carlo Approach}

We use micro data from the Romanian Labor Force Survey to analyze the effect of the restructuring process on the employment dynamics of urban residents in the Romanian labor market. We analyze the way personal characteristics influence individuals' ability to adjust to labor market transformations. Sequential employment decisions made by individuals are modeled as Markov decision processes. The resulting multivariate probit models are estimated using Markov Chain Monte Carlo techniques.

JEL Classification: C15, C35, J23

Keywords: Employment dynamics, transition economy, Markov chain Monte Carlo

Alexandru Voicu

Institute for the Study of Labor (IZA)

P.O. Box 7240

D-53072 Bonn

Germany

Tel.: +492283894527

Fax: +492283894510

Email: voicu@iza.org 


\section{Introduction}

The study of labor market performance in transition economies has received a great deal of attention in the economic literature of recent years. An important component of the process of transition to a market economy, experienced by Central and East-European countries, is the emergence of labor markets. The restructuring process has involved a massive reallocation of labor under the influence of changes in productivity, demand shocks and changes in the the incentive structure. With very few exceptions, the countries in the region have experienced a sharp increase in unemployment. The rates of long-term unemployment have increased dramatically and many long-term job seekers have left the market. The uneven incidence of unemployment across country regions as well as across socio-economic and demographic groups has widened existing labor market imbalances. Numerous studies document the changes in labor markets since the beginning of transition. Barr (1994), Boeri (1994), Commander and Coricelli (1995), Commander and Tolstopiatenko (1997) use macro data to provide accounts of the evolution of employment, unemployment, and labor markets and the evolution of related social policies.

Through the effect on labor markets, the economic restructuring process has placed a heavy burden on social support systems and the labor market adjustment process. The reduction of employment and the increase in unemployment has increased the social security burden placing it on an ever shrinking part of the working population. Disparities in unemployment incidence lead to permanent reductions in the effective labor supply by discouraging the long-term unemployed, which may, in turn, lead to a further widening of the existing disparities. This long-term phenomenon has two main effects. First, it increases the pressure on the social support systems and, second, regional imbalances in the incidence of unemployment may mobilize communities against further reductions in employment, thereby delaying the restructuring process in high unemployment areas. Therefore, identifying the trends in labor market evolutions as well as the disequilibria affecting labor market adjustments is important in designing an effective social safety net and active labor market policies aimed at facilitating the restructuring process.

The study of individual labor force histories provides an important insight on the effect of privatization and restructuring on the labor markets. Generally, such studies measure the effects of personal characteristics, labor market conditions, and active labor market policies on individuals' labor market experience. The results lead to the identification of imbalances across socio-economic groups and locations. Secondly, the restructuring process cannot be construed as and equilibrium process. It is very likely that the number of factors influencing the process as well as the magnitude of their respective effects change over time. Studies of individual labor force histories, using flexible frameworks, can provide an accurate description of this process.

A fast growing body of literature uses the study of individual labor force histories to document the evolution in the Central and East European labor markets in the period following the fall of the communist regimes. A comprehensive 
review of this literature is provided in Svejnar (1999). From an econometric point of view, most of the papers analyzing individual labor market histories can be classified in two broad categories: a) studies that use duration models and b) studies that model individuals' transitions among the labor force states as a Markov chain process. Most of the studies in the first category estimate the duration of unemployment as a function of personal characteristics and labor market conditions. The micro data sets used are suitable to the estimation of hazard functions, have a relatively small number of observations and, generally, are not publicly available. In this category, the most relevant examples are Ham et al. (1998), Ham et al. (1999), Finta and Terrel (1997), Abraham and Vodopivec (1993), Micklewright and Nagy $(1995,1997)$, and Earle and Pauna (1998). The results vary in significance but they all find that age and higher education have a positive effects on the probability of exiting unemployment. Vocational training or, more generally, a high level of firm and industry specific skills is found to improve the chances of finding a job by Ham et al. (1998) and Ham et al. (1999) while Earle and Pauna (1998) find a weak negative effect of specific skills on the probability of exiting unemployment.

The studies in the second category model individuals' experiences as a Markov chain process. The Markov chain process is characterized by a transition matrix. The probabilities that form the transition matrix are parametrized as function of individuals' characteristics and labor market conditions. Certain dimensions of the transition matrix are then estimated, generally using multinomial logit models. The data sets used are large panels constructed from labor force survey data. Again, the effects of personal characteristics on the individuals' labor force histories vary widely in significance and sign. Age is found to have a weak positive effect of the probability of exiting unemployment by Storm and Terrell (1997). Using categorical definition of age, Bellman (1995) and Earle(1997) find that older individuals have a lower probability of finding a job and a higher probability of dropping out of the labor force. Jones and Kato (1997) find higher education and experience increase women's chances of finding jobs.

All the studies mentioned above share one important feature which has been rarely, if ever, mentioned. The economic transition provides the perfect empirical framework for studying the effect of education and type of skills on workers' mobility and ability to adapt to changing labor market conditions. It is widely accepted that educational choice is endogenous to the labor supply decision. Thus, under normal conditions, the study of labor supply as a function of educational attainment is likely to be affected by endogeneity bias. In a transition economy setting, however, most individuals made the education decisions prior to the beginning of transition, and, the overwhelming majority, without expecting any major change. As a result, the sudden changes in labor markets brought about by the transition process provide a natural experiment for labor supply studies.

The studies in the second category, to which the present paper is related, have two major drawbacks. First, all of them use panels no longer then two periods, even when longer panels are available. Secondly, to our knowledge, none of the study estimates the full model. The Markov chain model of individual 
histories requires that the individual's contributions to the likelihood function describes the individual's full history (the product of the probability occupying the initial state and the transition probabilities corresponding to the individual's history) (Amemya, 1985). The papers we review in this section use a different approach. First, the sample is divided in subsamples corresponding to initial states. Then the estimation is carried out separately for each sub sample generally using multinomial logit models. This approach precludes any meaningful comparison across sub samples of the effects of independent variables on transition probabilities. Moreover, selection bias is likely to affect the results since the sub-sample used is selected based on the value of the dependent variable in the previous period.

In this paper we use micro data from the Romanian Labor Force Survey to analyze the effect of privatization on the Romanian labor market. We document the uneven incidence of unemployment in general and long term unemployment in particular across several dimensions - age, gender and education. A two-state model of labor force participation is estimated with a three-period panel data set. The estimation method used overcomes the problems common to dynamic participation models. Participation decisions made by individuals are modeled as Markov decision processes. The resulting multivariate probit models are estimated using Markov Chain Monte Carlo methods introduced by Chib and Greenberg (1998). The method allows a high degree of flexibility in the construction of the model and in specifying the correlation matrix for the multivariate probit model. It also avoids the convergence problems that hamper the maximum likelihood estimation.

The remainder of the paper is organized as follows. The next section contains a short description of the economic restructuring process in Romania and the presentation of the data set. The empirical specification and the estimation proceedure are presented in section three, followed by the results and the concluding remarks.

\section{$2 \quad$ Background and data}

Four important components of the restructuring process affected the labor markets in the period to which this study refers:

1. Privatization of the state sector.

2. Restructuring of the remaining state owned enterprises.

3. Creation of a new private sector.

4. The emergence of the private agricultural sector follwing land reform legislation.

Compared to the more advanced transition economies, in Romania, the restructuring process took place at a slow pace in the early 1990s. In spite of the slow pace at which they proceeded, the privatization and restructuring of the state sector, and the emergence of the new private sector had a strong effect on the labor market. In non-agricultural sectors, approximately 1,241,000 jobs (approx. 25 percent of the total) were lost between 1992 and 1996 most of them 
in large firms in manufacturing sectors, transportation, extraction of crude oil and construction. In the same period only slightly more than 700,000 new jobs were created mainly in small firms. The sectors the fared best in job creation were manufacturing of wood products, trade, utilities, services. This pattern of job creation and destruction indicates the presence an intense process of intersectoral reallocation of labor. Earle (1997) provides a detailed study of labor reallocation among industrial sectors.

The net effect of the process was the reduction of the number of jobs by more than 10 percent between 1992 and 1996. Yet, in the same period both the labor force participation and the unemployment rate remained remarkably stable. The participation rate hovered around 73 percent and registered unemployment, after reaching 11 percent in 1994, fell to about 7 percent in 1996. This somehow puzzling situation may be due the sharp increase in employment in agricultural sector.

The emergence of the private agricultural sector induced a large discrepancy between the observed labor market behavior of individuals living in urban and rural areas. Elsewhere (Voicu,(2001)), we discuss the effect of land reform legislation on labor market transformation. The results indicated that urban and rural residents are affected by different reallocation mechanisms. Rural residents experienced an important increase in employment driven by flows into agriculture from both non-participation and employment in the non-agricultural sector. The private agricultural sector, on the other hand played no role for urban residents. It is not enough, therefore, to reduce the role of the urban/rural location to a mere shift in the value of a latent utility function. Rather, the two groups should be treated separately. In this paper we concentrate on labor market experiences of urban residents.

We draw our data from the Romanian Labor Force Survey, conducted in March 1994 and March 1995. The questionnaire was administered on a representative sample of Romanian households, selected on the basis the population census conducted in January 1992. This survey contains standard labor force participation and unemployment questions about the current status of the respondent. For the purpose of analyzing labor market transitions, it also has two important features. First, the survey contains retrospective questions about the labor market activity of the respondent the year prior to the survey. Thus, we are able to use the 1993 labor market status of the participants in the 1994 survey. The other feature is that nearly all of the respondents in 1994 were re-interviewed in the 1995 survey. With some effort, it is possible to match unambiguously nearly all the cases. Thus, we were able to construct a three-period panel with 12594 observations, including the retrospective information on labor market activity in 1993.

Among the variables in the data set, education deserves special attention. Educational levels as described in the survey differ not only in terms of years of schooling necessary to attain a certain level but also in terms of industry specific, firm specifics, and managerial skills.

The level of education is described by the following seven categories: primary school, gymnasium, vocational, high school, foreman, post-high-school training 
(in presenting the results, I refer to this category as HIPLUS), and university. In the Romanian educational system primary school represents the first four years of education. The gymnasium consists of the next four years. After completing the first eight years, a gymnasium graduate may choose either to go to high school or vocational school. The vocational schools are usually run by big industrial firms or co-op associations and provide students with a high level of specific skills. The degree of specificity varies from firm-specific to branch- or sector-specific. Usually, it takes two years to complete vocational school, and at graduation such students are offered a job by the firm that runs the school. Unlike vocational schools, highschool provides students only with general skills. After completing the high school, one may choose either to go to a university or to enter the labor market. There are also two other forms of formal training distinguished in this survey. The post-high school training can be pursued by the high school graduates and provides students with branch specific skills. Foreman schools provide both technical (branch specific) and managerial training. Firms enroll their employees in the foreman schools and pay all the expenses.

The sample composition by individual characteristics used in this study is presented in table 1 . The first thing to note is the relatively large proportion of individuals with low level of education. Another interesting fact that twice as many men have acquired specific-skill education while a larger proportion of women opted for general highschool education.

Table 1. Sample composition

\begin{tabular}{||l|rlr||}
\hline \hline TOTAL & \multicolumn{3}{|c||}{22835} \\
Gender & Female & Male & Total \\
Education & 6340 & 6254 & 12594 \\
Primary & $394(6.21 \%)$ & $295(4.72 \%)$ & Total \\
Gymnasium & $1739(27.43 \%)$ & $1184(18.93 \%)$ & 2923 \\
Vocational & $991(15.63 \%)$ & $1895(30.30 \%)$ & 2886 \\
High-school & $2261(34.95 \%)$ & $1443(23.07 \%)$ & 3659 \\
Foreman & $46(0.73 \%)$ & $419(6.70 \%)$ & 465 \\
HIPLUS & $364(5.74 \%)$ & $223(3.57 \%)$ & 587 \\
University & $590(9.31 \%)$ & $795(12.71 \%)$ & 1385 \\
Age & Female & Male & Total \\
Mean & 35.42 & 37.07 & 37.08 \\
\hline \hline
\end{tabular}

The transition matrices displayed in tables 2a-3c reveal that an important number of individuals (10-13 percent) changed states every year, with roughly 15 percent changing states over a two year period. The trend becomes more intense in 1994-1995 as the restructuring process picked up in intensity. Three percent of the individual in the sample change states twice in the same time period (table $2 \mathrm{~d}$ ). The discrepancy that initially existed between flows in and out of employment has been reversed in 1994-1995 so that for a two year period transition matrix appears remarkably balanced. Individuals younger than 
19 account for more than 20 percent of the non-employed and for 15 percent of the inflows into employment while individuals younger that 25 (the age at which one typically finishes university) make up 50 percent of the inflows into unemployment.

Table 2a. Transition matrix 1993-1994 1994-1995

\begin{tabular}{|c|c|c|c|c|}
\hline & & \multicolumn{3}{|c|}{1994} \\
\hline & & $\bar{E}$ & $\mathrm{NE}$ & Total \\
\hline \multirow{3}{*}{1993} & $\mathrm{E}$ & 7650 & 613 & 8263 \\
\hline & $\mathrm{NE}$ & 515 & 3816 & 4331 \\
\hline & Total & 8165 & 4429 & 12594 \\
\hline
\end{tabular}

Table 2b. Transition matrix

\begin{tabular}{|l|l|l|l|l|}
\cline { 3 - 5 } \multicolumn{2}{c|}{} & \multicolumn{3}{c|}{1995} \\
\cline { 3 - 5 } \multicolumn{2}{c|}{1994} & $\mathrm{E}$ & NE & Total \\
\cline { 2 - 5 } & NE & 8436 & 729 & 8165 \\
\cline { 2 - 5 } & Total & 8271 & 4323 & 4429 \\
\hline
\end{tabular}

Table 2c. Transition matrix 1993-1995

\begin{tabular}{|c|l|l|l|l|}
\cline { 3 - 5 } \multicolumn{2}{c|}{} & \multicolumn{3}{|c|}{1995} \\
\cline { 3 - 5 } 1993 & $\mathrm{E}$ & 7301 & 962 & 8263 \\
\cline { 2 - 5 } & NE & 970 & 3361 & 4331 \\
\cline { 2 - 5 } & Total & 8271 & 4323 & 12594 \\
\hline
\end{tabular}

Table 2d. Complete labor force histories

\begin{tabular}{|l|l|l|l|}
\hline \multicolumn{3}{|c|}{ Status } & Observations \\
\hline 1993 & 1994 & 1995 & \\
\hline $\mathrm{E}$ & $\mathrm{E}$ & $\mathrm{E}$ & 7090 \\
\hline $\mathrm{E}$ & $\mathrm{E}$ & $\mathrm{NE}$ & 560 \\
\hline $\mathrm{E}$ & $\mathrm{NE}$ & $\mathrm{E}$ & 211 \\
\hline $\mathrm{NE}$ & $\mathrm{E}$ & $\mathrm{E}$ & 346 \\
\hline $\mathrm{E}$ & $\mathrm{NE}$ & $\mathrm{NE}$ & 402 \\
\hline $\mathrm{NE}$ & $\mathrm{E}$ & $\mathrm{NE}$ & 169 \\
\hline $\mathrm{NE}$ & $\mathrm{NE}$ & $\mathrm{E}$ & 624 \\
\hline $\mathrm{NE}$ & $\mathrm{NE}$ & $\mathrm{NE}$ & 3192 \\
\hline
\end{tabular}

The empirical analysis in the following section will be using a two-state model (employed/not employed). Before proceeding, however, it is important to mention that a large number of job-to-job transitions have taken place between 1993 an 1995. Some 13 percent of the employed individuals have changed ownership forms. While some of the transitions in this table may be due to change in ownership of certain firms, the small number of firms privatized in this period cannot account for the important proportion of movers. Earle (1997) provides a description of job-to-job flows in the same period from a different perspectiveintersectoral flows. Finally, in our sample, more than 40 percent of the flows in and out of employment involve unemployment. 


\section{Empirical specification}

In this paper we study the employment dynamics in an economy undergoing an extensive privatization process. Studies of labor force supply have been categorized by Heckman (1993) in labor supply choices at the extensive margin (labor force participation and employment choices) and choices at the intensive margin (choices about hours of work or weeks of work for workers). This study falls into the first category, as we are interested in decision to participate or be employed and not in the number of hours worked.

The empirical specification employed is consistent with the results of search models, which are often used in dynamic labor supply studies (for example, Hyslop, 1999). Each period individuals receive one wage offer from the known distribution of wages. Denote the distribution of wages by $F\left(w ; \mu, \sigma_{1}^{2}\right)$ where $\mu$ and $\sigma_{1}^{2}$ are the mean and the variance of the distribution. We assume that the conditional mean is a linear function of personal characteristics and that the variance does not depend on the personal characteristics. Denote the distribution of wages, conditional on personal characteristics by $F_{\mid X}\left(w ; X_{1} \alpha, \sigma_{1}^{2}\right)$. The wage offer can then be represented as

$$
W=X_{1} \alpha+\epsilon_{1}, \epsilon_{1} \sim\left(0, \sigma_{1}^{2}\right)
$$

The wage offer is compared with the individual's reservation wage. In the setting of search models, the reservation wage is the result of a dynamic optimization problem. For a given individual, the reservation wage is deterministic since it is a function of the known parameters of the dynamic optimization problem. The reservation wage, however is not observed by the econometrician. From the econometrician's perspective reservation wage is a random variable that depends on personal characteristics in the following manner:

$$
W^{*}=X_{1} \gamma+X_{2} \delta+\epsilon_{2}
$$

where $X_{1}$ is the set of personal characteristics which determine the mean of the wage offer, $X_{2}$ is a set of personal characteristics that influence the reservation wage only and $\epsilon_{2}$ are i.i.d. $\left(0, \sigma_{2}^{2}\right)$.

We further assume that personal characteristics are time invariant. We assume, however, that their effects on the wage and reservation wage change with time. This assumption allows for possible changes in the wage offer distribution facing an individual and for a variable reservation wage. Under these assumptions, the wage and reservation wage become, respectively,

$$
\begin{aligned}
& w_{i t}=X_{1 i} \alpha_{t}+\epsilon_{1 i t} \\
& w_{i t}^{*}=X_{1 i} \gamma_{t}+X_{2 i} \delta_{t}+\epsilon_{2 i t}
\end{aligned}
$$


The reduced-form specification of the dynamic employment decision becomes $y_{i t}=I\left(w_{i t}-w_{i t}^{*}>0\right)$ or,

$$
y_{i t}=I\left(X_{1 i}\left(\alpha_{t}-\gamma_{t}\right)-X_{2 i} \delta_{t}+\epsilon_{1 i t}-\epsilon_{2 i t}>0\right)
$$

Denote $X=\left[X_{1} \mid X_{2}\right], \beta_{t}=\left[\begin{array}{c}\alpha_{t}-\gamma_{t} \\ \delta_{t}\end{array}\right]$ and $u_{i t}=\epsilon_{1 i t}-\epsilon_{2 i t}$. It follows:

$$
y_{i t}=I\left(X_{i} \beta_{t}+u_{i t}>0\right)
$$

where $u_{i t}$ is assumed to be normally distributed, $E\left[u_{i t}\right]=0, u_{i t}$ are independent over $i$ 's and to have a correlation structure over $t$ given be the following correlation matrix:

$$
\Sigma=\left[\begin{array}{ccccc}
1 & \sigma_{12} & \sigma_{13} & \ldots & \sigma_{1 T} \\
\sigma_{21} & 1 & \sigma_{23} & \ldots . & \sigma_{2 T} \\
\sigma_{32} & \sigma_{32} & 1 & \ldots . & \sigma_{3 T} \\
\cdot & \cdot & \cdot & \ldots . & \cdot \\
\cdot & \cdot & \cdot & \ldots & \cdot \\
\sigma_{T 1} & \sigma_{T 2} & \sigma_{T 3} & \ldots . & \sigma_{T T}
\end{array}\right]
$$

where $t=1 \ldots T$.

Under these assumptions, the dynamic employment decision model becomes a multivariate probit model. We estimate this model for a three-period panel using Markov Chain Monte Carlo methods.

The binary dependent variable $y_{i t}=1$ if individual $i$ works at time $t$ and $y_{i t}=0$ otherwise. $X_{i}$ is a vector of time invariant personal characteristics that affect the individual's participation decision and $\beta_{t}$ are time variant coefficients. Thus, we allow the effect of personal characteristics on employment decision to vary over time. The components of $X$ are: rural/urban location, gender, age, and education - a categorical variable with seven categories.

The model defined this way is a multivariate probit model. We estimate it using the MCMC algorithm introduced by Chib and Greenberg (1998). The goal in Bayesian estimation is constructing the posterior distributions for the parameters of interest by integrating the joint posterior distribution. When the number of parameters is large or the model is complicated analytical integration is not possible. Numerical integration can be performed by deterministic or simulation-based methods. Markov chain Monte Carlo (MCMC) algorithms are simulation-based integration methods. A sample must be drawn from the multivariate distribution of interest. This is accomplished by constructing a Markov chain which has a equilibrium distribution that is the distribution of interest. The key element of the chain is the transition kernel, a conditional probability density. The most popular MCMC methods are the Gibbs sampler and the Metropolis-Hastings algorithm. The Gibbs sampler uses a transition 
kernel based on conditional distributions. Full conditional distributions have to be known and available for sampling. The Metropolis-Hastings algorithm is a more flexible algorithm which uses a kernel based on a candidate distribution and an acception/rejection scheme.

In this paper I use a hybrid algorithm proposed by Chib and Greenberg (1998) - the Gibbs sampler with a Metropolis Hastings step. Using the same approach as data augmentation (Tanner and Wong, 1987) the joint posterior distribution is modified by introducing a latent variable $Z$. The new posterior distribution is:

$$
\pi(\beta, \sigma, Z \mid y) \propto \pi(\beta, \sigma) f(Z \mid \beta, \Sigma) \operatorname{pr}(y \mid Z, \beta, \sigma)
$$

where $\beta$ is a vector of coefficients, $\sigma$ is a vector containing the free elements of the correlation matrix.

Conditional on $Z_{i}, \operatorname{pr}\left(y_{i} \mid Z_{i}, \beta, \sigma\right)=I\left(Z_{i} \in B_{i}\right)$ where $B_{i}$ is the inverse mapping of $y_{i t}=I\left(z_{i t}>0\right)$. The posterior distribution becomes

$$
\pi(\beta, \sigma, Z \mid y) \propto \pi(\beta, \sigma) \prod_{i} f\left(Z_{i} \mid \beta, \Sigma\right) I\left(Z_{i} \in B_{i}\right)
$$

where

$$
f\left(Z_{i} \mid \beta, \Sigma\right) \propto|\Sigma|^{-\frac{1}{2}} \exp \left\{-\frac{1}{2}\left(Z_{i}-X_{i} \beta\right)^{\prime} \Sigma^{-1}\left(Z_{i}-X_{i} \beta\right)\right\} I(\sigma \in C)
$$

and $C$ is the set where the elements of the correlation matrix are defined.

Regarding the latent variable as a parameter, we then sample from the conditional distributions:

- Conditional distribution of $Z_{i}$

$$
\left[Z_{i} \mid y_{i}, \beta, \Sigma\right] \propto \phi_{T}\left(Z_{i} \mid X_{i} \beta, \Sigma\right) \prod_{i}\left\{I\left(z_{i t}>0\right) I\left(y_{i t}=1\right)+I\left(z_{i t} \leq 0\right) I\left(y_{i t}=0\right)\right\}
$$

To draw from a truncated normal distribution, I used the method proposed by Geweke (1991), which consists of running a Gibbs sub-chain with T steps within the main Gibbs sampler cycle.

- Conditional Distribution of $\beta$

We assume prior independence between $\beta$ and $\sigma$. The prior distribution of $\beta$ is a k-variate normal distribution $\pi(\beta)=\phi_{k}\left(\beta \mid \beta_{0}, B_{0}^{-1}\right)$. Conditional distribution is 


$$
[\beta \mid Z, \Sigma] \sim N_{k}\left(\beta \mid \hat{\beta}, B^{-1}\right)
$$

where $\hat{\beta}=B^{-1}\left(B_{0} \beta_{0}+\sum_{i=1}^{n} X_{i}^{\prime} \Sigma^{-1} Z_{i}\right)$ and $B=B_{0}+\sum_{i=1}^{n} X_{i}^{\prime} \Sigma^{-1} X_{i}$

- Conditional Distribution of $\sigma$

$$
\begin{gathered}
\pi(\sigma \mid Z, \beta) \propto \pi(\sigma) f(Z \mid \beta, \Sigma) \\
f(Z \mid \beta, \Sigma) \propto|\Sigma|^{-\frac{n}{2}} \exp \left\{-\frac{1}{2} \operatorname{tr}\left(Z^{*}-\Delta\right)^{\prime} \Sigma^{-1}\left(Z^{*}-\Delta\right)\right\} I(\sigma \in C) \\
Z^{*}=\left(Z_{1}, \ldots, Z_{n}\right) \text { and } \Delta=\left(X_{1} \beta, \ldots, X_{n} \beta\right) .
\end{gathered}
$$

Prior distribution of $\sigma$ is a normal distribution truncated at $C$.

$$
\pi(\sigma) \propto \phi_{p}\left(\sigma \mid \sigma_{0}, G_{0}^{-1}\right), \sigma \in C
$$

where $p$ is the number of free parameters in the correlation matrix.

To draw from this distribution I use a MH step within the Gibbs sampler.

Convergence of the chain is assessed using the method proposed by Gelman and Rubin (1992) with the modified correction factor proposed by Brooks and Gelman (1998). One preliminary run of 15000 iterations, with OLS coefficients as starting values, was used to construct starting values for three independent chains. The starting values were extreme values chosen form the posterior distribution of the coefficients. The three independent chains, each with 15000 iterations and the initial run were used to compute the scale reduction factor. We also evaluated the convergence criterion proposed by Geweke(1992) based on a single chain which uses spectral density estimates of the series. Both criteria indicated that the chain converges fast to the stationary distribution.

The prior distribution of $\beta$ is multivariate normal with a mean vector of 0 and a variance matrix of 100 times the identity matrix. The prior distribution of the elements of the correlation matrix is multivariate normal with a mean vector of 0 and a variance matrix equal to 10 times the identity matrix. The proposal density used to generate candidate values in the MH step is $q\left(\phi \mid \sigma_{i}^{k}\right)=$ $s * g\left(\phi-\sigma_{i}^{k}\right)$ where $g$ is the standard normal distribution and $s$ is the step size. We use a step size $s=1000 / N$. 


\section{Results}

Table 4 reports the posterior means, the posterior standard deviation (PSTD), and the numerical standard errors (NSE) for the $\beta s$ and the scale reduction factors $(\mathrm{R})$. The values of $\mathrm{R}$ very close to 1 indicate convergence. The interpretation of the $\beta$ is the same as that in a linear regression model with dependent variable $Z_{i t}$. Results indicate that men are more likely to be employed and the gender difference is widening over time. More education and firm/industry-specific skills improved an individual's likelihood of being employed. Over time, university educated workers continue to have the brightest employment prospects. While firm- and industry-specific skills continue to be an important factor, their effect on the probability of being employed diminished relative to high level of education. The coefficients of age and age squared are large indicating the strong concavity of the latent variable. The posterior moments for the correlation coefficients are presented in Table 5. The first thing to note is the high correlation of the three error terms. From a technical point of view, this validates the choice of a multivariate probit model for this application. Imposing restrictions on the form of the correlation matrix (for example estimating the model as an independent probit model) would have led to incorrect inferences. The high positive correlation coefficients indicate that unobserved heterogeneity and state dependence influence individuals' work histories. The correlation declining with time interval indicates the presence of an autocorrelated component of the stochastic process governing employment decisions. The decline in the one period correlation hints towards a non-stationary such process. The non-stationarity does not come as a surprise given the fact that labor reallocation at the beginning of the transition period can hardly be regarded as an equilibrium process. 
Table 4. Moments of the posterior distribution for the coefficients.

\begin{tabular}{||l|l|l|l|l||}
\hline \hline Variable & \multicolumn{4}{|c||}{1993} \\
\cline { 2 - 5 } Const. & mean & PSTD & NSE & $\mathrm{R}$ \\
\cline { 2 - 5 } Gender & -7.879 & 0.1510 & 0.0040 & 1.0034 \\
Age & 0.389 & 0.0300 & 0.0002 & 1.0004 \\
Age`2 & 0.425 & 0.0078 & 0.0002 & 1.0031 \\
Gymnasium & -0.534 & 0.0102 & 0.0002 & 1.0027 \\
Vocational & 0.175 & 0.0617 & 0.0010 & 1.0013 \\
Foreman & 0.677 & 0.0637 & 0.0010 & 1.0012 \\
High school & 0.715 & 0.0985 & 0.0006 & 1.0008 \\
HIPLUS & 0.965 & 0.0619 & 0.0007 & 1.0006 \\
University & 1.143 & 0.0891 & 0.0014 & 1.0013 \\
\hline \hline Variable & \multicolumn{5}{|c||}{1994} & 0.0014 & 1.0018 \\
\cline { 2 - 5 } & mean & PSTD & NSE & R \\
\cline { 2 - 5 } Const. & -6.649 & 0.1410 & 0.0011 & 1.0002 \\
Gender & 0.481 & 0.0290 & 0.0002 & 1.0003 \\
Age & 0.368 & 0.0074 & 0.0001 & 1.0005 \\
Age`2 & -0.475 & 0.0098 & 0.0001 & 1.0005 \\
Gymnasium & 0.104 & 0.0612 & 0.0004 & 1.0002 \\
Vocational & 0.524 & 0.0625 & 0.0008 & 1.0007 \\
Foreman & 0.806 & 0.0975 & 0.0010 & 1.0007 \\
High school & 0.599 & 0.0616 & 0.0007 & 1.0006 \\
HIPLUS & 0.935 & 0.0882 & 0.0008 & 1.0003 \\
University & 1.209 & 0.0739 & 0.0007 & 1.0006 \\
\hline \hline \hline Variable & \multicolumn{5}{|c||}{1995} \\
\cline { 2 - 5 } Const. & mean & PSTD & NSE & $\mathrm{R}$ \\
\cline { 2 - 5 } Gender & -5.785 & 0.1333 & 0.0014 & 1.0005 \\
Age & 0.496 & 0.0287 & 0.0005 & 1.0014 \\
Age`2 & 0.336 & 0.0071 & 0.0001 & 1.0008 \\
Gymnasium & -0.447 & 0.0095 & 0.0001 & 1.0008 \\
Vocational & 0.432 & 0.0599 & 0.0006 & 1.0004 \\
Foreman & 0.693 & 0.0616 & 0.0004 & 1.0001 \\
Highschool & 0.481 & 0.0603 & 0.0004 & 1.0001 \\
HIPLUS & 0.926 & 0.0876 & 0.0003 & 1.0002 \\
University & 1.153 & 0.0740 & 0.0004 & 1.0002 \\
\hline \hline
\end{tabular}


Table 5. Moments of the posterior distribution for correlation coefficients.

\begin{tabular}{||c|c|c|l|l||}
\hline \hline & \multicolumn{4}{|c||}{ work94 } \\
\cline { 2 - 5 } work93-work94 & mean & pop. std. & NSE & $\mathrm{R}$ \\
work93-work95 & 0.381 & 0.0088 & 0.0001 & 1.0001 \\
work94-work95 & 0.411 & 0.0094 & 0.0001 & 1.0003 \\
\hline \hline
\end{tabular}

It is important to note that the $\beta$ measure the effects of personal characteristics on the latent variables. Individuals' employment decisions depend, however, on the latent variables crossing a certain threshold ( 0 in our case) and labor market histories are sequences of employment decisions. To completely describe the effect of personal characteristics on individuals' experiences, we calculate their effect on the probabilities of three types of events:

1. Probability of being employed in each of the three years of the panel.

2. Probability of transition between participation and non-participation.

3. Conditional probability of transition between participation and non-participation.

4. Probability that individuals experience complete paths (for example they are employed in all three years).

The probabilities are calculated for 14 categories of individuals who differ with respect to their gender and education. For each category, we estimate the above probabilities at all ages between 16 and 65 . In a three-period twostate model, there are eight possible histories. The probability of a complete history is the cumulative distribution function (CDF) of a trivariate normal distribution. To calculate the normal CDFs, we use the GHK smooth recursive simulator (Geweke,1989; Hajivassiliou,1990; and Keane, 1994. Greene, 1997). The probabilities corresponding to the eight possible histories are evaluated at the posterior means ${ }^{1}$. The employment probabilities and the transition probabilities are calculated by adding the probabilities of the relevant histories.

The marginal effects of personal characteristics on employment probabilities are summarized if table 6 . The entries in the table are estimated coefficients in linear regressions of estimated employment proabilities on presonal characteristics. Unless otherwise noted the coefficients are significant at 95 percent level of confidence.

\footnotetext{
${ }^{1}$ We have also used an alternative approach for computing the probabilities: for all categories we computed the probabilities at each Gibbs sampler step, checked the convergence of the quantities using Geweke's single-chain convergence measure (CD). The results were very similar with much higher computational cost.
} 
Table 6. Employment Probabilities. Marginal effects.

\begin{tabular}{||l|l|l|l||}
\hline \hline Variable & Emp 93 & Emp 94 & Emp 95 \\
\cline { 2 - 4 } Const. & -1.778 & -1.571 & -1.383 \\
Gender & 0.096 & 0.126 & 0.130 \\
Age & 0.125 & 0.112 & 0.104 \\
Age`2 & -0.156 & -0.141 & -0.131 \\
Gymnasium & 0.048 & 0.030 & 0.010 \\
Vocational & 0.180 & 0.148 & 0.123 \\
Foreman & 0.213 & 0.221 & 0.192 \\
Highschool & 0.188 & 0.168 & 0.136 \\
HIPLUS & 0.248 & 0.253 & 0.248 \\
University & 0.287 & 0.314 & 0.298 \\
\hline \hline
\end{tabular}

Employment probabilities are strongly concave functions of age. Individuals with high level of education and those with specific skills (foreman and HIPLUS) maintain a high employment probability for a longer period of time, which leads to a flattening of top of the employment probability-age profile (figure 1) for those categories. Over time, individuals with ages roughly between 30 and 50 have experienced a decrease in employment probability for both genders and for most types of education (figure 2). The situation is more dramatic for women who have seen larger drops for wider age ranges, across all educational categories. Individuals with university education or specific skills (foreman and HIPLUS) fare relatively better. The employment probability of young individuals has increased over time for both genders and almost all categories of education. This situation may reflect a better capacity to adapt to labor market transformation, improved employment opportunities for younger individuals as well as increased ability to work while pursuing a form of higher education. The employment probability of individuals around retirement age rose significantly over time, mostly for university educated people and those with specific skills (foreman and HIPLUS).

Men have higher employment probabilities in all years, for all levels of education (figure 1). The difference is larger for low levels of education and smaller for highly educated individuals and those with specific skills. Gender difference has maxima colse to the extremes of the age range due to women's child bearing and lower retirement age. Over time, the gender difference in employment probability has increased significantly. This effect is stronger for lower educated individuals but also for individuals for some categories of individuals with specific skills (foreman and vocational) for which employment in the restructuring industrial sector has a larger share.

Education has two important effects on employment probability. First, high level of education (university) and high level of specific skills (foreman and HIPLUS) have higher employment probabilities for all ages. Second, the higher the level of education or the level of specific skills the longer an individuals will maintain a high level of employment probability (figure 3). Over time the effect of education has increased, as can be inferred from the spacing out of the age-probability profiles in figure 3 and the change in education coefficients . 
This phenomenon was more intense for women, while workers with general skills (highschool) and those with vocational training incurred the largest relative loss.

To analyze the dynamic patterns in employment, we estimate the probabilities of transition between employment and non-employment as well as the conditional transition probabilities. The transition probabilities describe individuals' mobility (the likelihood of experiencing many transitions across labor force states). For groups with high turnover rates, the net inflows into employment provide a basis for inference on long-term labor market prospects. Tables $7 \mathrm{a}$ and $7 \mathrm{~b}$ present the estimated marginal effects of personal characteristics on transition probabilities. As the age-probability profile for the transitions in and out of employment are not quadratic, for these probabilities we used a specification that includes a polinomial of third degree in age.

Table 7a. Transition Probabilities. Marginal effects.

\begin{tabular}{||l|l|l|l|l||}
\hline \hline Variable & E93-E94 & E94-E95 & E93-NE94 & E94-NE95 \\
\cline { 2 - 5 } Const. & -1.928 & -1.748 & 0.360 & 0.603 \\
Gender & 0.123 & 0.143 & -0.027 & -0.018 \\
Age & 0.123 & 0.113 & -0.024 & -0.042 \\
Age`2 & -0.151 & -0.139 & 0.070 & 0.111 \\
Age`3 & & & -0.006 & -0.009 \\
Gymnasium & 0.040 & 0.021 & 0.008 & 0.009 \\
Vocational & 0.175 & 0.145 & 0.005 & 0.003 \\
Foreman & 0.236 & 0.226 & -0.023 & -0.005 \\
Highschool & 0.191 & 0.164 & -0.003 & 0.005 \\
HIPLUS & 0.275 & 0.278 & -0.026 & -0.025 \\
University & 0.333 & 0.346 & -0.046 & -0.031 \\
\hline \hline
\end{tabular}

Table 7b. Transition Probabilities. Marginal effects.

\begin{tabular}{||l|l|l|l|l||}
\hline \hline Variable & NE93-E94 & NE94-E95 & NE93-NE94 & NE94-NE95 \\
\cline { 2 - 5 } Const. & 0.559 & 0.802 & 2.546 & 2.319 \\
Gender & 0.002 & -0.013 & -0.098 & -0.112 \\
Age & -0.028 & -0.045 & -0.117 & -0.106 \\
Age`2/100 & 0.055 & 0.099 & 0.146 & 0.133 \\
Age^3/1000 & -0.004 & -0.007 & & \\
Gymnasium & -0.010 & -0.011 & -0.038 & -0.019 \\
Vocational & -0.027 & -0.022 & -0.154 & -0.127 \\
Foreman & -0.015 & -0.034 & -0.199 & -0.187 \\
Highschool & -0.023 & -0.027 & -0.165 & -0.141 \\
HIPLUS & -0.022 & -0.030 & -0.227 & -0.223 \\
University & -0.019 & -0.048 & -0.268 & -0.267 \\
\hline \hline
\end{tabular}

For all ages and categories of education, women have lower probabilities of staying employed and higher probabilities of remaining unemployed. Women experience higher turnover rates, as both the probability of entering and leaving employment are larger across educational categories and age. Higher education and specific skills improve the probability of staying employed, while reducing the probability of remaining in the non-working state and the overall chance 
of experiencing transitions over labor force states. The net employment inflows show (figure 4) a disproportionately large outflow of women in 1993-1994, for all categories of education except university degree. The net employment inflows are positive for young individuals and negative for most individuals, age 35 or older. Throughout the period, women experience smaller positive net inflows and larger negative net inflows, which indicates a widening gap between the employment probabilities of men and women. Between 1993-1994, the largest negative net inflows have been experienced by workers with vocational training. The situation has changed in the next interval when workers with high level of specific skills (foreman) and individuals with general training (highschool) have seen the largest negative inflows. This result is consistent with the theory that a high level of firm specific skills would reduce the probability of a layoff in the initial phase of the restructuring process. The bimodal shape of the age-probability profiles for flows both in and out of employment tell a very interesting story (figure 5,6). The probability of exiting employment has peaks around 55 year of age and 25 years. While the first one is most likely due to workers accepting early retirement packages, the second one indicates that younger workers are more likely to lose their jobs. The reverse is true for the probability of entering employment. Young individuals first entering labor market are responsible for the large probability values at ages around 25 . The secondary mode around 55 years of age means that some of those who accepted early retirement packages found jobs, most likely in the newly created private sector.

Transition probabilities give important insights into the labor reallocation process. The inference, however, is heavily influenced by the two natural processes mentioned above: a large proportion of young workers entering the labor force for the first time and older workers leaving the labor force through retirement. The large number of individuals affected by these processes artificially inflate or deflate the importance of flows at the extremes of the age range so that the transition probabilities at this ages appear larger relative to the midrange age. One way to partially filter out these effects is to study the conditional transition probabilities.

Indeed, while the probability of leaving employment of individuals around age 20 ranges between 0.1 and 0.2 , depending on gender and education, conditional on being employed in the first period, the probability of the same event moves in the range $0.2-0.6$ (figure 7 ). This finding strengthens the result afforded by the study of transition probabilities. Not only young individuals are more likely to become unemployed but the proportion of those who will is extremely high. At the other end of the age spectrum, the large number of individuals who have retired exaggerates the importance of the inflows into employment for older individuals. The probability of finding a job conditional on not working in the first period is relatively small. Roughly, 10 to 30 percent of 60 -year-old individuals return to work if not employed compared to 50 to 90 percent for 40-year-old workers (figure 8).

For all levels of education and ages, women have higher probabilities of loosing their jobs if employed (figure 9) and lower probabilities of finding new jobs if 
unemployed (figure 10). High educated workers (university) and workers with a high level of specific skills (foreman and HIPLUS) have lower probabilities of losing their jobs if employed (figure 7) and have better job prospects if unemployed (figure 8).

Comparison of conditional employment probabilities with the marginal probabilities allow very interesting inference into the dynamic nature of the employment decisions. Typically, dynamic employment decisions are represented by dynamic probit models where the past binary dependent variable enters the specification of the current employment decision. The estimated coefficients define the employment probability conditional on the past period status. If the employment decision is characterized by strong persistence (past status explained most of the present status), it is reasonable to expect that the role of personal characteristics will fade. Notwithstanding the difference in distributional and functional form assumptions, the multivariate probit model allows the estimation of conditional employment probabilities. If we compare the marginal employment probabilities with the conditional employment probabilities we can infer the effect of post status on present employment decision. Table $8 \mathrm{a}$ and $8 \mathrm{~b}$ compare the marginal employment probability with the employment probability conditional on past status, for 1994 and 1995. Clearly, the past decisions play an important role in current decisions. Not only the age-probability profile shifts up when we condition on past employment status but also the effects of personal characteristics is smaller in all cases. The difference between the numbers in the last two columns of the tables could be interpreted as the marginal effects of the past status (for the constant term) and marginal effects of interaction terms between past status and personal characteristics. From this angle, it is interesting to note that the effects of gender, foreman, HIPLUS, and university education on employment probability are stronger when we condition on nonemployment in the past period. Employment in the previous period increases the probability of being employed in the current period with 0.3 . This value represents the difference in intercepts (when age equals zero). Graphical analysis of the estimated $P\left(E_{t} \mid E_{t-1}\right)-P\left(E_{t} \mid N E_{t-1}\right)$ indicated that the quantity remains positive across the gender, education, and the entire age range. The difference declines over time indicating a reduction in the persistence of employment decision, consistent with the declining one-period correlation coefficient (figure 12). 
Table 8a. Marginal and conditional employment probabilities, 1994

\begin{tabular}{||l|l|l|l||}
\hline \hline Variable & E94 & E94|E93 & E94|NE93 \\
\cline { 2 - 4 } Const. & -1.571 & -0.906 & -1.206 \\
Gender & 0.126 & 0.108 & 0.124 \\
Age & 0.112 & 0.084 & 0.086 \\
Age`2 & -0.141 & -0.108 & -0.108 \\
Gymnasium & 0.030 & 0.018 & 0.017 \\
Vocational & 0.148 & 0.109 & 0.108 \\
Foreman & 0.221 & 0.179 & 0.192 \\
Highschool & 0.168 & 0.129 & 0.131 \\
HIPLUS & 0.253 & 0.202 & 0.220 \\
University & 0.314 & 0.254 & 0.294 \\
\hline \hline
\end{tabular}

Table 8b. Marginal and conditional employment probabilities, 1995

\begin{tabular}{||l|l|l|l||}
\hline \hline Variable & E95 & E95|E94 & E95|NE94 \\
\cline { 2 - 4 } Const. & -1.383 & -0.814 & -1.097 \\
Gender & 0.130 & 0.104 & 0.120 \\
Age & 0.104 & 0.081 & 0.082 \\
Age^2 & -0.131 & -0.104 & -0.104 \\
Gymnasium & $0.010^{*}$ & $0.001^{*}$ & $0.002^{*}$ \\
Vocational & 0.123 & 0.091 & 0.096 \\
Foreman & 0.192 & 0.145 & 0.157 \\
Highschool & 0.136 & 0.099 & 0.105 \\
HIPLUS & 0.248 & 0.194 & 0.223 \\
University & 0.298 & 0.230 & 0.272 \\
\hline \hline
\end{tabular}

* Not significant

Finally, we explore the effect of personal characteristics on the probability of individuals experiencing entire paths. We are particularly interested in the probability of long-term employment (employed in all three time periods), the probability of long term unemployment (not employed in all three years), and the probability of that an individual is employed in 1993, unemployed in 1994, and employed again in 1995. Table 9 gives the marginal probabilities for each of these three events. Men have larger long-term employment probability and a smaller long-term unemployment probability, regardless of education and age. University educated workers and those with high-level specific skills have a better chance to be employed in all three years and smaller unemployment probabilities. Workers in these educational categories maintain high employment probabilities for a wider age range. Individuals at the extremes of the age range are more likely to experience temporary joblessness spells (figure 11). Men and workers with university education or high levels of specific skills are less likely to lose their jobs temporarily. 
Table 9. Probabilities of entire histories. marginal effects

\begin{tabular}{||l|l|l|l||}
\hline \hline Variable & E-E-E & NE-NE-NE & E-NE-E \\
\cline { 2 - 4 } Const. & -1.688 & 2.051 & 0.047 \\
Gender & 0.135 & -0.092 & -0.008 \\
Age & 0.110 & 0.100 & $-0.001^{*}$ \\
Age`2 & -0.140 & -0.130 & -0.011 \\
Age^3 & & & -0.002 \\
Gymnasium & 0.029 & -0.026 & 0.001 \\
Vocational & 0.160 & -0.129 & $0.003^{*}$ \\
Foreman & 0.230 & -0.173 & -0.008 \\
Highschool & 0.176 & -0.139 & $-0.001^{*}$ \\
HIPLUS & 0.281 & -0.203 & $-0.006^{* *}$ \\
University & 0.345 & -0.237 & -0.017 \\
\hline \hline
\end{tabular}

* Not significant ; ${ }^{* *}$ significant at 90 percent

\section{Conclusions}

We investigate the effect of the restructuring process on the Romanian labor market. The data were collected at the beginning of the transition process. Despite of the slow pace of the restructuring process in its initial phase, there were strong indications of important labor reallocation processes. Our approach is to study the individual labor market histories. We were primarily interested in estimating the effects of personal characteristics on individuals' labor market experiences during the transition process.

We employed a two-state model to study employment dynamics. A multivariate probit model is used as empirical specification of the individual employment decisions. The model was estimated using MCMC methods. The model and the estimation procedure bring a substantial improvement over existing studies. The model allows for time variant coefficients, a departure from the stationary transition probability matrix typically assumed. Secondly, the estimation method requires no simplifying parametrization of the correlation matrix.

Results indicate that personal characteristics have a strong influence on employment decisions. Sequential employment decisions exhibit a strong but declining persistence. We found that women have lower employment probabilities in all years, for all ages and educational categories. This gap is widening as, throughout the period, women experienced larger employment outflows and smaller inflows. Women have lower long-term employment rates and are more likely to experience long-term unemployment. Women's turnover rates are significantly higher than those of men.

We model the latent variable driving employment decisions as a quadratic function of age. As a result the employment probability-age profile is strongly concave. There are large estimated differences in employment probability between individuals at the extremes of the age range and the individuals in the middle. High education and high levels of specific skills help individuals main- 
tain high employment probabilities for longer periods of time. Workers with ages at the two ends of the age range have higher probabilities of both entering and leaving employment. This feature is explained by fact that young individuals have a higher probability of being labor force entrants and a relatively higher probability of losing their jobs, while older workers have a high rate of labor force exit through early retirement a relatively high propensity of finding post retirement jobs in the new private sector. After filtering out the effect of new entries and retirement we found that both young and old individuals have higher probabilities of losing their jobs if employed and lower probabilities of finding new jobs if unemployed.

Results paint an interesting picture of the effect of education on labor market experience. We can divide the educational categories in four distinct groups based on the consistency of their effects. The first group, low education level, consists of primary and gymnasium categories. While gymnasium educated individuals outperform those with primary education, the large difference between them and the other educational categories justifies putting them in the same group. The second group is formed by two educational categories that, a priori, seemed unlikely partners, highschool (general skills) and vocational education (sector specific skills). Consistently, highschool education seems to have an advantage but the difference between the two categories is hardly significant. The next group is formed by individuals with foreman training (managerial / high level of firm- and sector-specific skills) and post-highschool education (high level of specific skills). Within this third group individuals with post-highschool education consistently outperform those in foreman category. One reason for this situation may be the larger probability of individuals in the latter category to hold jobs in the industrial sector, the main target of the restructuring process. Finally, university education forms a "one-category group" consistently outperforming in all respects all other levels of education. From the low-education group to the university-educated category an individual's employment probability increases, the probability of losing his or her job if employed decreases, the probability of finding a new job if unemployed improves, the net inflows into employment are more favorable, the prospects of long-term employment are better and the turnover rates are lower. Aside from the low-education group the individuals with the poorest labor market performance are those with vocational training. Their specialized skills reduce their mobility and, thus, their ability to adjust to labor market transformations.

From a policy point of view the findings are interesting in several respects. The widening gap between men and women suggests that active labor market policies are necessary to improve women's participation. High education proved to be an important determinant of good labor market performance. High education provides individuals with high mobility and improves their ability to relocate to new growing sectors. The relatively small proportion of population in this educational category may explain the overall poor performance of the Romanian economy. Policies designed to improve access to higher education, as well as an increase in the importance given to general training are necessary to improve individuals' labor market performance and the performance of the 
overall economy.

High proportion of workers with specific training lead to the belief that the work force is well qualified and this would insure a smooth transition process. We found evidence that high specialization (vocational training) reduces workers mobility. Since transition involves reallocation of labor across sectors, highly specialized workers will have a hard time finding new jobs in the newly emerging sectors. This study adds to the growing concern that, the large proportion of workers with specifying training and their strong ties with the shrinking industrial sector will rather have a negative effect on the speed of economic restructuring. Retraining programs are necessary to help workers find jobs in different sectors. Also a shift of focus in vocational education from heavy industry to the growing sectors is necessary. 


\section{References}

Abraham, K. and M. Vodopivec, 1993, "Slovenia: A Study of Labor Market Transitions," mimeo. (The World Bank, Washington, DC).

Amemiya, T., 1985, Advanced Econometrics, Cambridge: Harvard University.

Barr, N., 1994. "Labour Markets and Social Policy in Central and Eastern Europe," New York.

Bellmann, L, S. Estrin, H. Lehman, and J. Wadsworth, 1995, "The Eastern German Labor Market in Transition: Gross Flow Estimates from Panel Data," Jornal of Comparative Economics, 20, 139-170.

Boeri, T., 1994, "Transitional Unemployment," Economics of Transition, 2, $1-25$.

Bound, J. et al., 1990, "Measurement Error in Cross-Sectional and Longitudinal Labor Market Surveys: Validation Study Evidence," Panel data and labor market studies, Hartog, Joop Ridder, Geert Theeuwes, Jules, eds., Contributions to Economic Analysis, vol. 192 Amsterdam; Oxford and Tokyo: North-Holland; distributed in the U.S. and Canada by Elsevier Science, New York, 1-19.

Chib, S., and E. Greenberg (1998), "Analysis of Multivariate Probit Models," Biometrika, 85, 347-361.

Commander, S. and F. Coricelli, 1995. "Unemployment and Restructuring in Eastern Europe and Russia," World Bank, Washington D.C.

Commander, S. and A. Tolstopiatenko, 1997. "Unemployment, Restructuring and the Pace of Transition," Lessons from the Economic Transition. Central and Eastern Europe, OECD.

Earle, J. S., 1997. "Industrial Decline and Labor Reallocation in Romania," SITE working paper.

Earle, J. S. and C. Pauna,1998, "Long-term Unemployment, Social Assistance and Labor Market Policies in Romania," Empirical Economics, 23, 203235 .

Finta, J. and K. Terrel, 1997, "Gender Differences in Flows Across Labor Market States in the Czech Republic," unpublished paper, (University of Michigan, Ann Arbor, MI.

Foley, M. C., 1997, "Determinants of unemployment Duration in Russia," Working paper no. 81 (The William Davidson Institute, University of Michigan Business School, Ann Arbor, MI. 
Geweke, J. (1989), "Bayesian Inference in Econometric Models Using Monte Carlo Integration," Econometrica, 57,1317-1340.

Geweke, J. (1991), "Efficient Simulation from the Multivariate Normal and Student-T Distributions Subject to Linear Constaraints." In Computing Science and Statistics: Proceedings of the 23rd Symposium on the Interface, Ed. E. Keramidas and S. Kaufman, 571-578, Fairfax Station, VA: Interface Foundation of North American.

Geweke, J. (1992), "Evaluating the Accuracy of Sampling-Based Approaches to the Calculation of Posterior Moments," Bayesian Statistics 4, ed. J.M. Bernardo, J.O. Berger, A.P. David, and A.F.M. Smith, 169-193.

Greene, W. H., 1997, Econometric Analyisis, Prentice Hall.

Hajivassiliou, V., 1990, "Smooth Simulation Estimation of Panel Data LDV Models," Department of Economics, Yale University.

Ham, J., J. Svejnar and K. Terrel, 1998, "Unemployment and Social Safety Net During Transitions to a Market Economy:Evidence from the Czech and Slovak Republics," American Economic Review, 88,1117-1142.

Ham, J., J. Svejnar and K. Terrel, 1999, "Women's Unemployment During Transition: Evidence from Czech and Slovak Micro-Data," Economics of Transition, 7, 47-78.

Heckman, J. J., 1993, "What Has Been Learned About Labor Supply in the Past Twenty Years?" American Economic Review, 83, 116-121.

Jones, D. C. and T. Kato, 1997, "The Nature and the Determinants of Labor Mrket Transitions in Former Communist Economies: Evidence from Bulgaria," Industrial Relations, 36, 229-254.

Hyslop, D., 1999, "State Depandence, Serial Correlation and Heterogeneity in Intertemporal Labor Force Participation of Married Women," Econometrica, 67, 1255-1294.

Keane, M., 1994, "A Computationally Practical Simulation Estimator for Panel Data," Econometrica, 62, 95-116.

Micklewright, J. and G. Nagy, 1995, "Unemployment Insurance and Incentives in Hungary," discussion paper no. 1118 (CEPR, London).

Micklewright, J. and G. Nagy, 1997, "The Implications of Exhausting Unemployment Insurance Entitlement in Hungary," occasional papers No. 58 (Economic and Social Policy Series, United nations Children's Fund).

OECD, 1998, OECD Economic Surveys, 1998, Romania. 
Storm, V. and K. Terrell, 1997, "Employment, Unemployment in Transition in the Czech Republic: Where Have All the Workers Gone?" mimeo, The William Davidson Institute, University of Michigan Business School, Ann Arbor, MI.

Svejnar, J., 1999, "Labor Markets in the Transitional Central and East European Economies," Handbook of Labor Economics, Volume 3, Elsevier Science.

Tanner, T. A., and Wong, W. H (1987), "The Calculation of Posterior Distributions by Data Augmentation," Journal of the American Statistical Association, 82, 528-549.

Voicu, A. (2001), "Labor Force Participation Dynamics in the Romanian Labor Market. A Bayesian Markov Chain Monte Carlo Approach" Ph.D. Thesis, Rutgers University. 
Figure 1: Employment probability
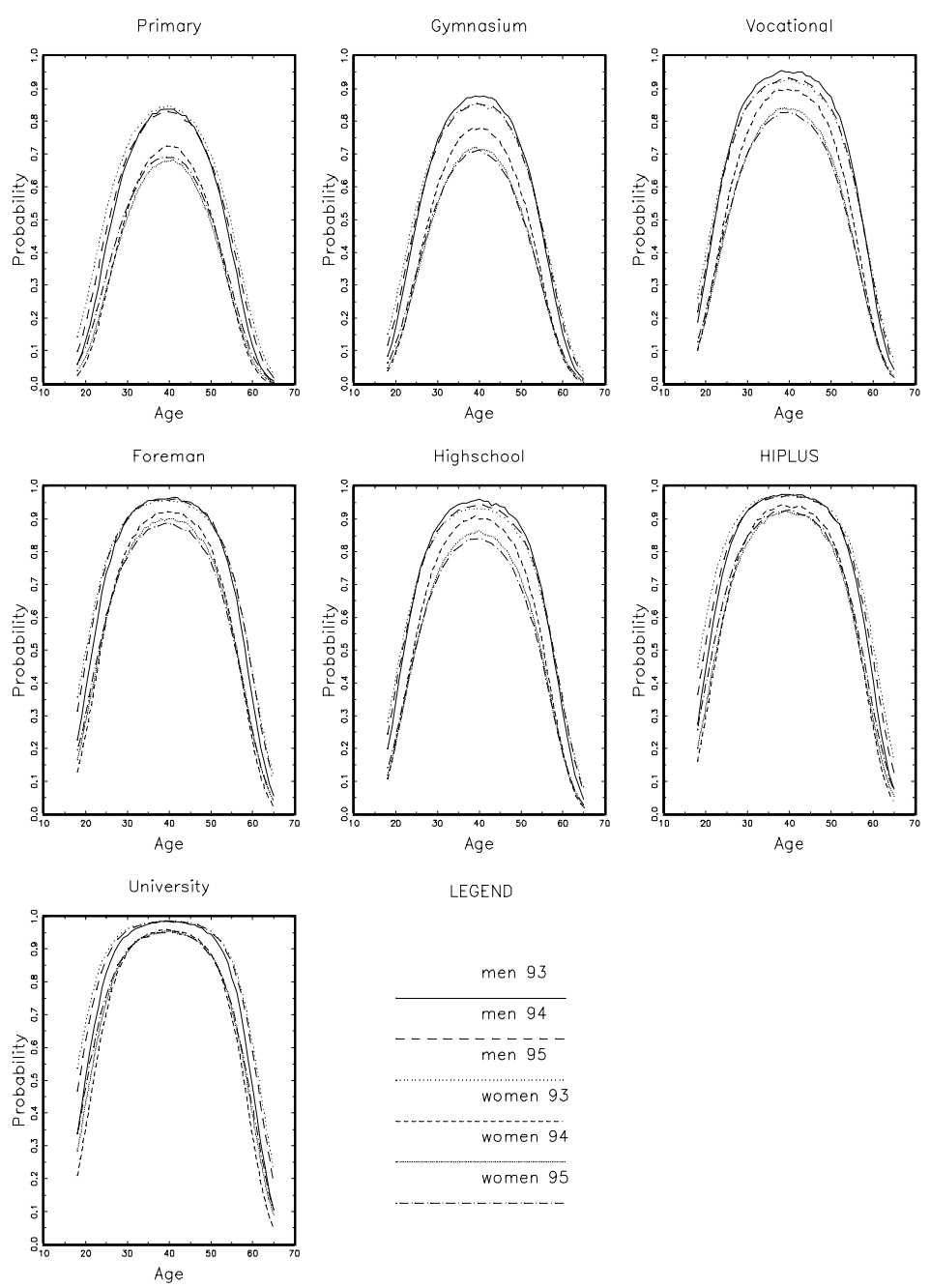

LEGEND

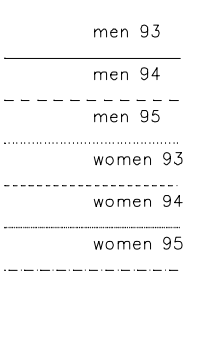


Figure 2: Change over time in employment probability
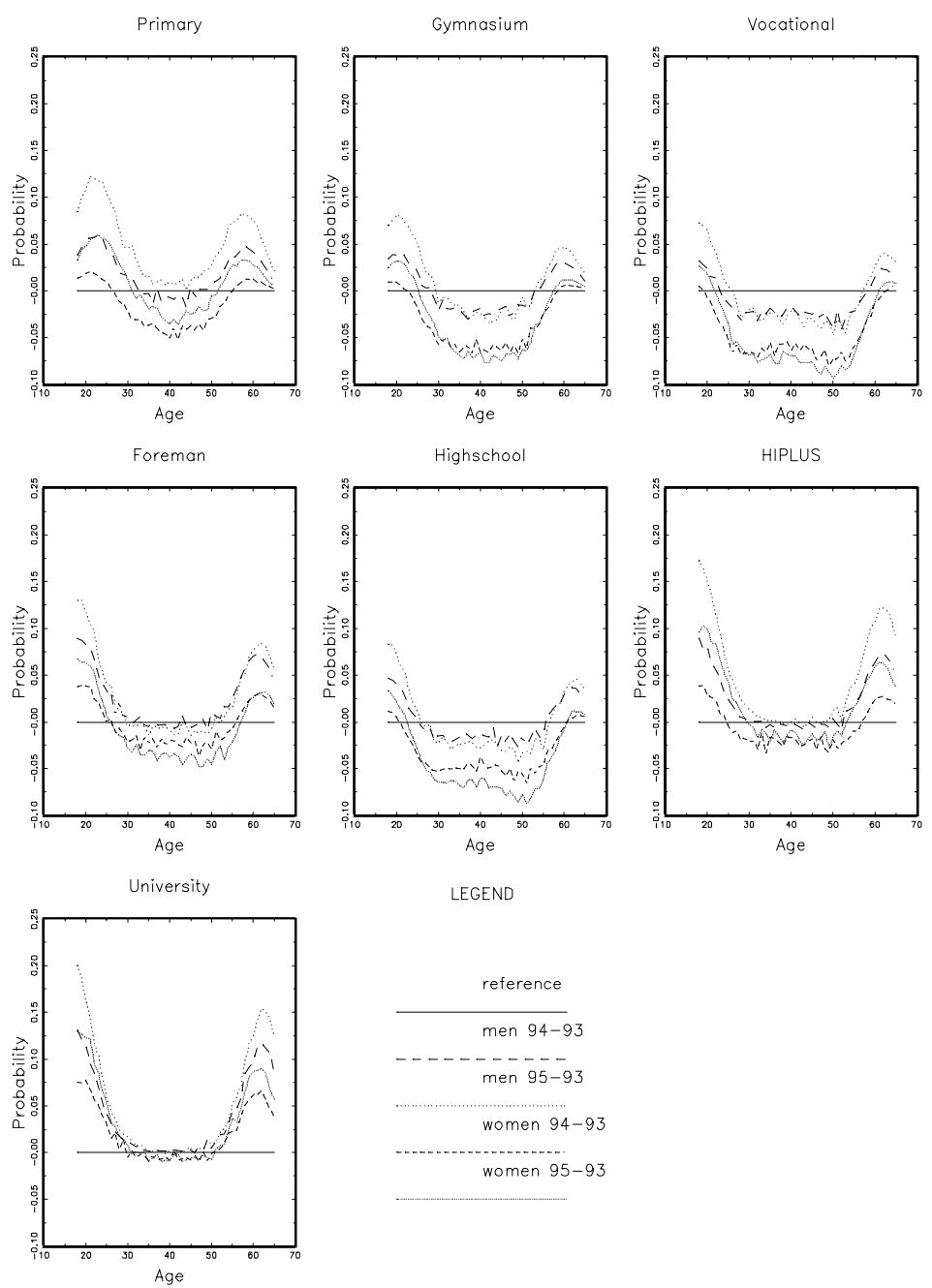
Figure 3: The effect of education on employment probability
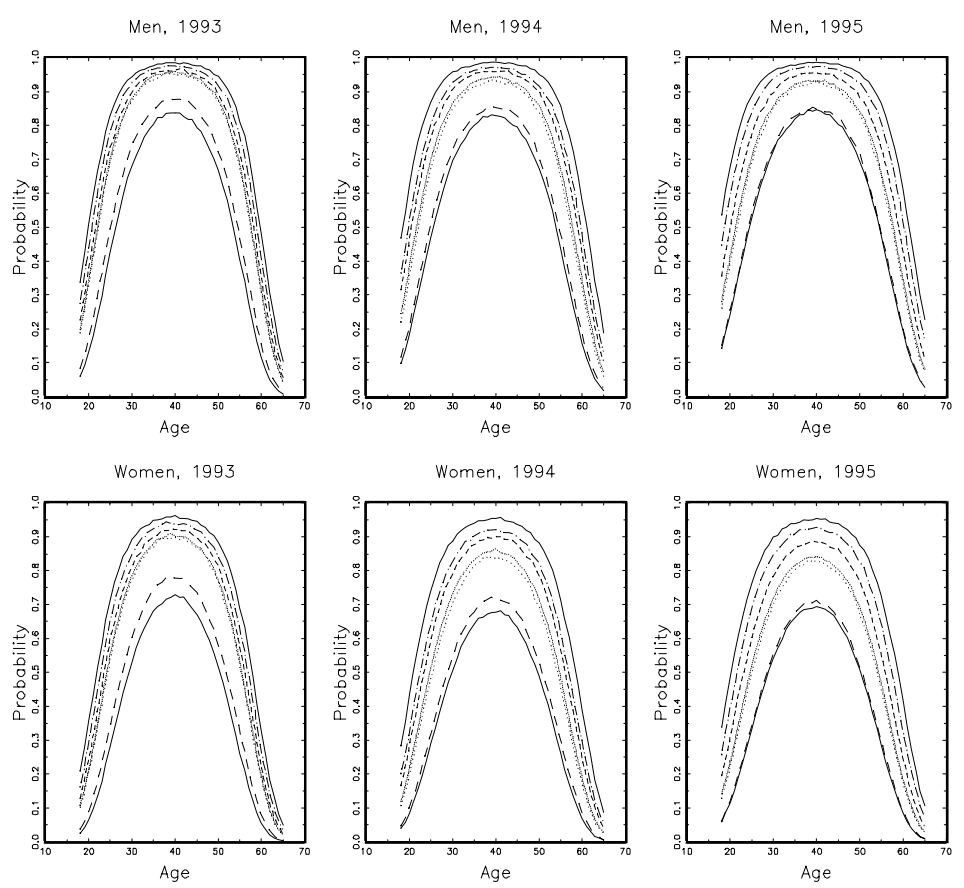

LEGEND

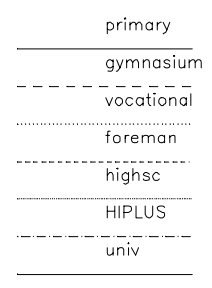


Figure 4: Net employment inflows
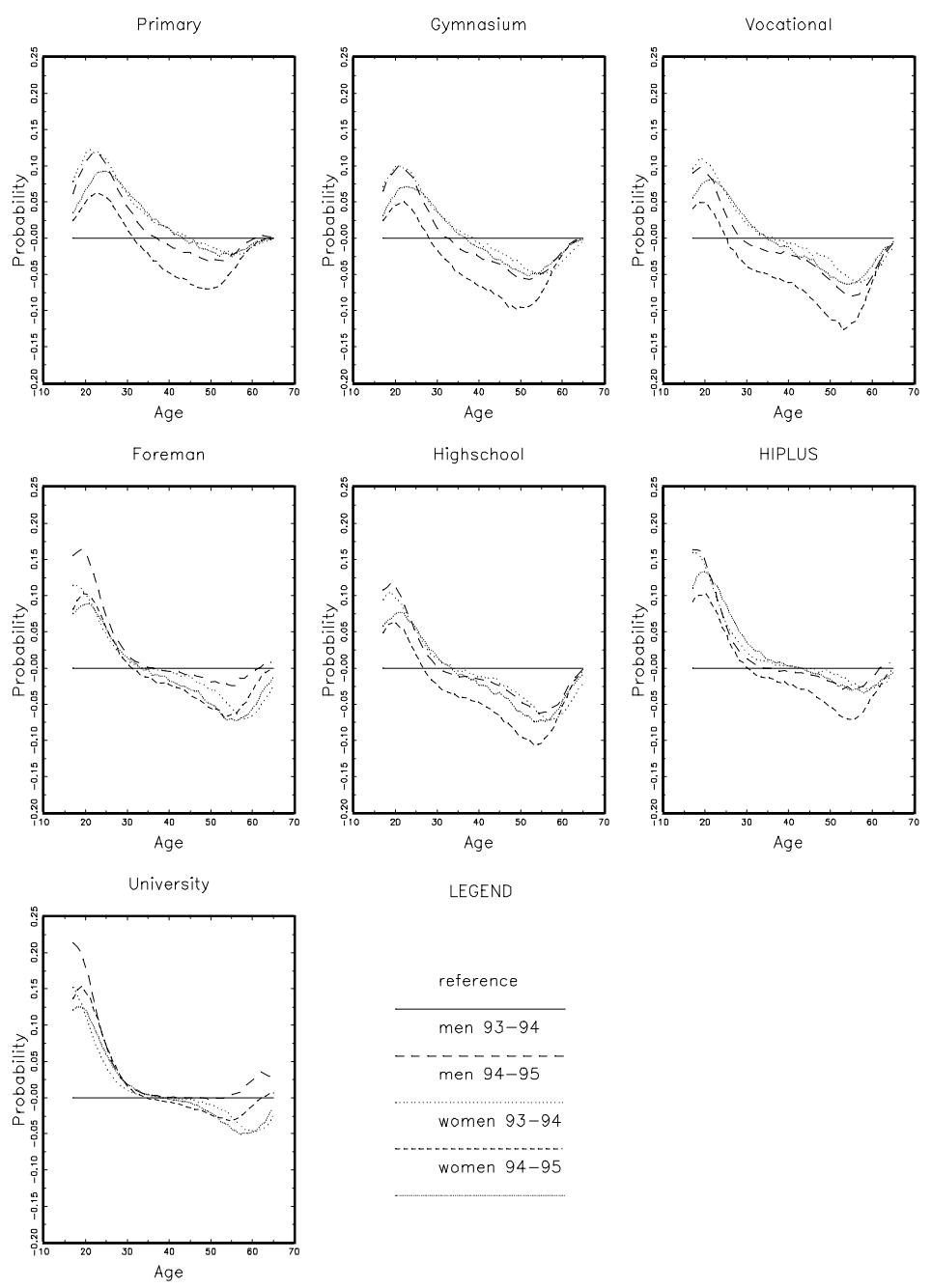

LEGEND

$$
\begin{gathered}
\text { reference } \\
\text { men } 93-94 \\
\hline \text { men } 94-95 \\
\text { women } 93-94 \\
\hline \text { women } 94-95
\end{gathered}
$$


Figure 5: Transition probabilities. Employment to non-employment.

Men, $1993-1994$

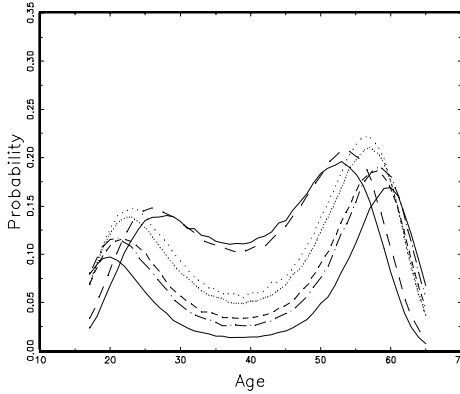

Women, $1993-1994$

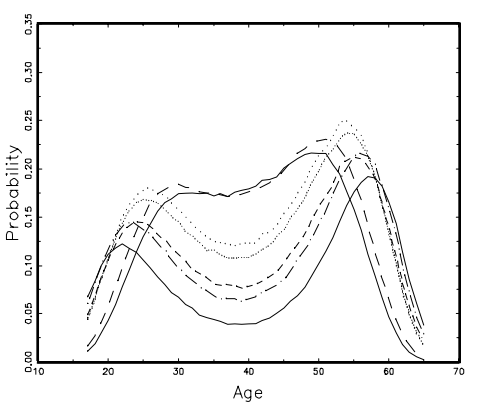

EGEND

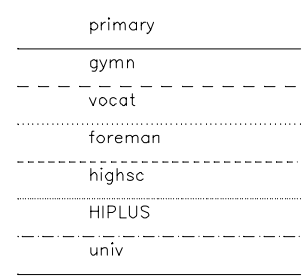

Men, $1994-1995$

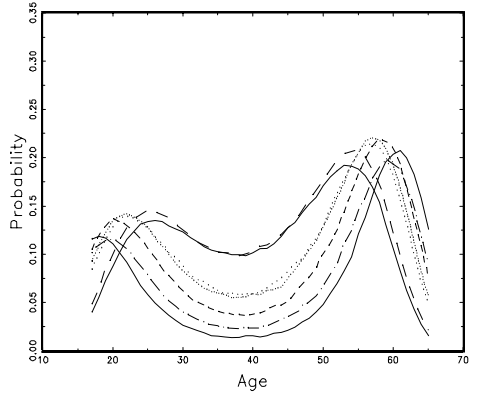

Women, $1994-1995$

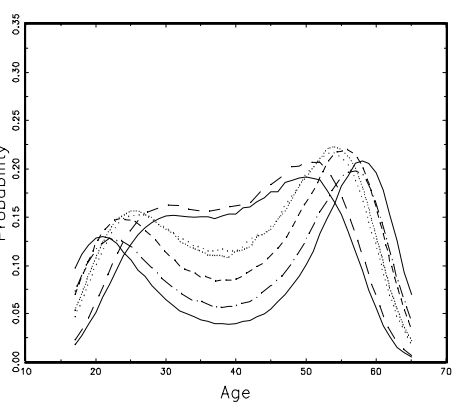


Figure 6: Transition probabilities. Non-employment to employment

Men, 1993-1994

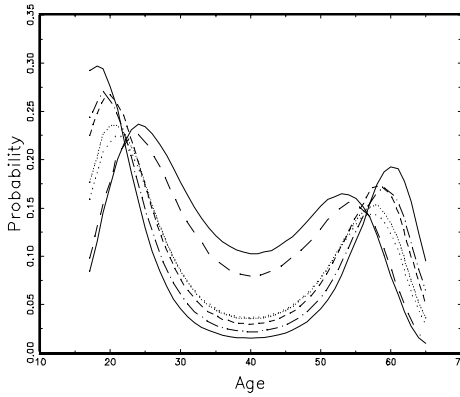

Women, 1993-1994

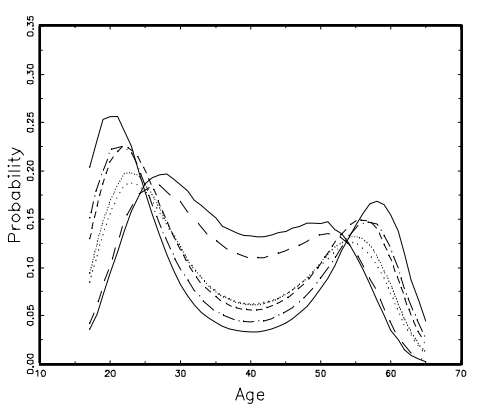

LEGEND

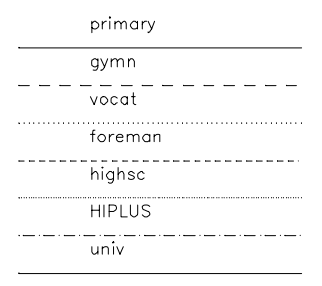

Men, 1994-1995

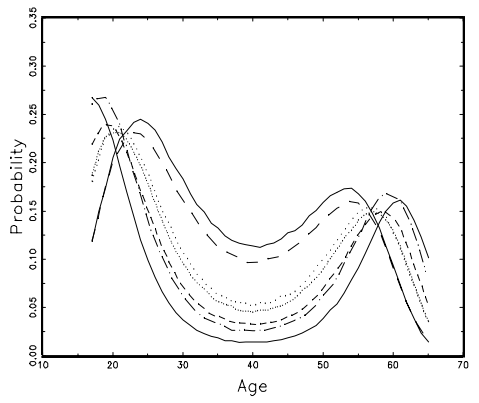

Women, $1994-1995$

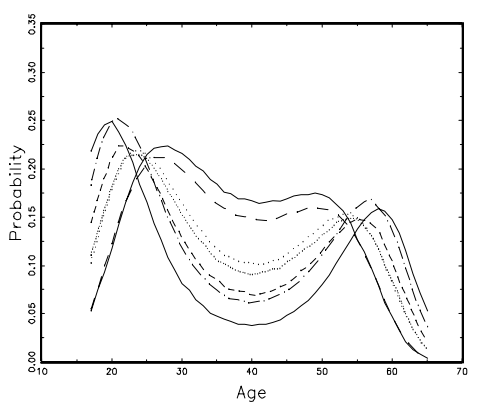


Figure 7: Conditional probability $P\left(N E_{t} \mid E_{t-1}\right)$
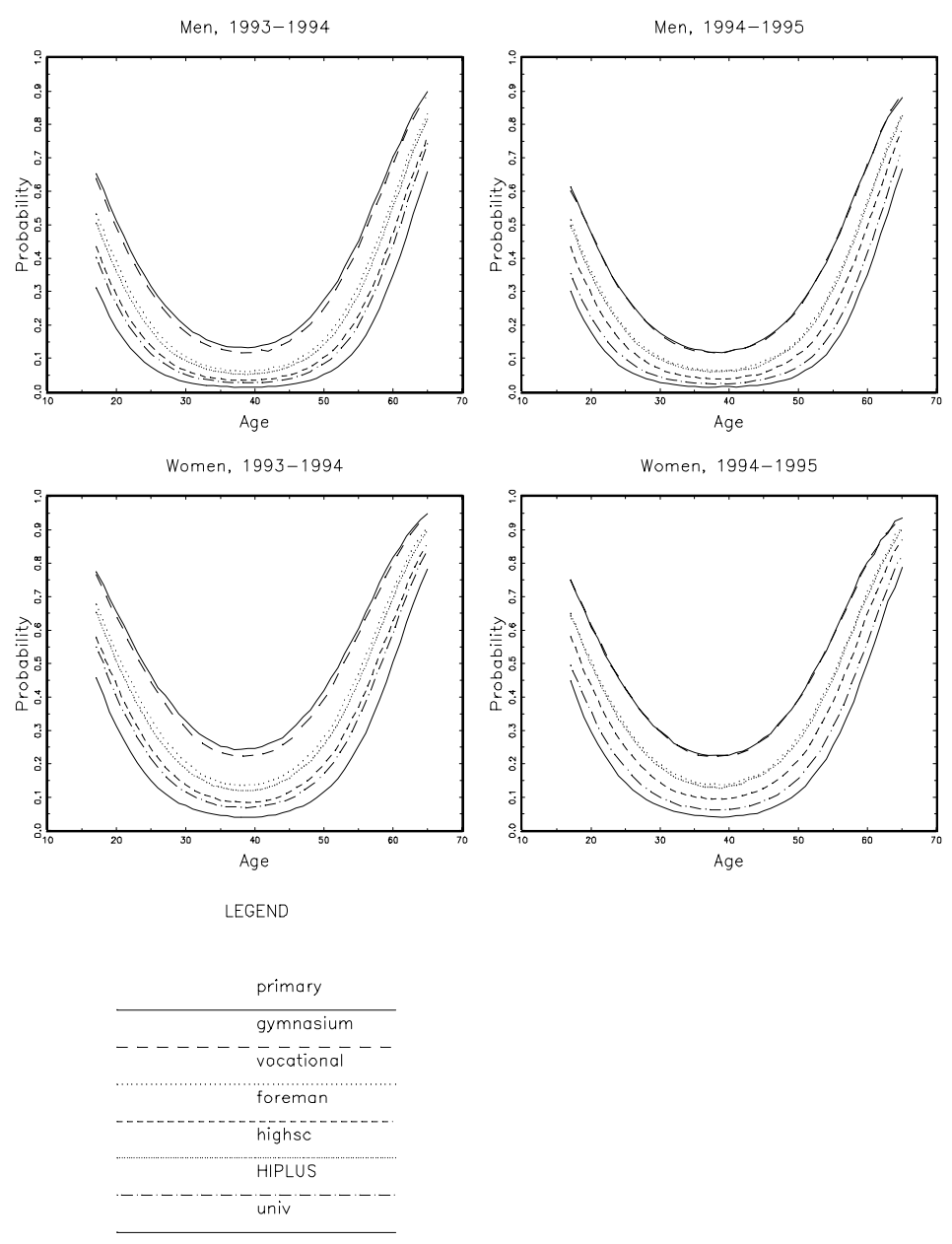
Figure 8: Conditional probability $P\left(E_{t} \mid N E_{t-1}\right)$
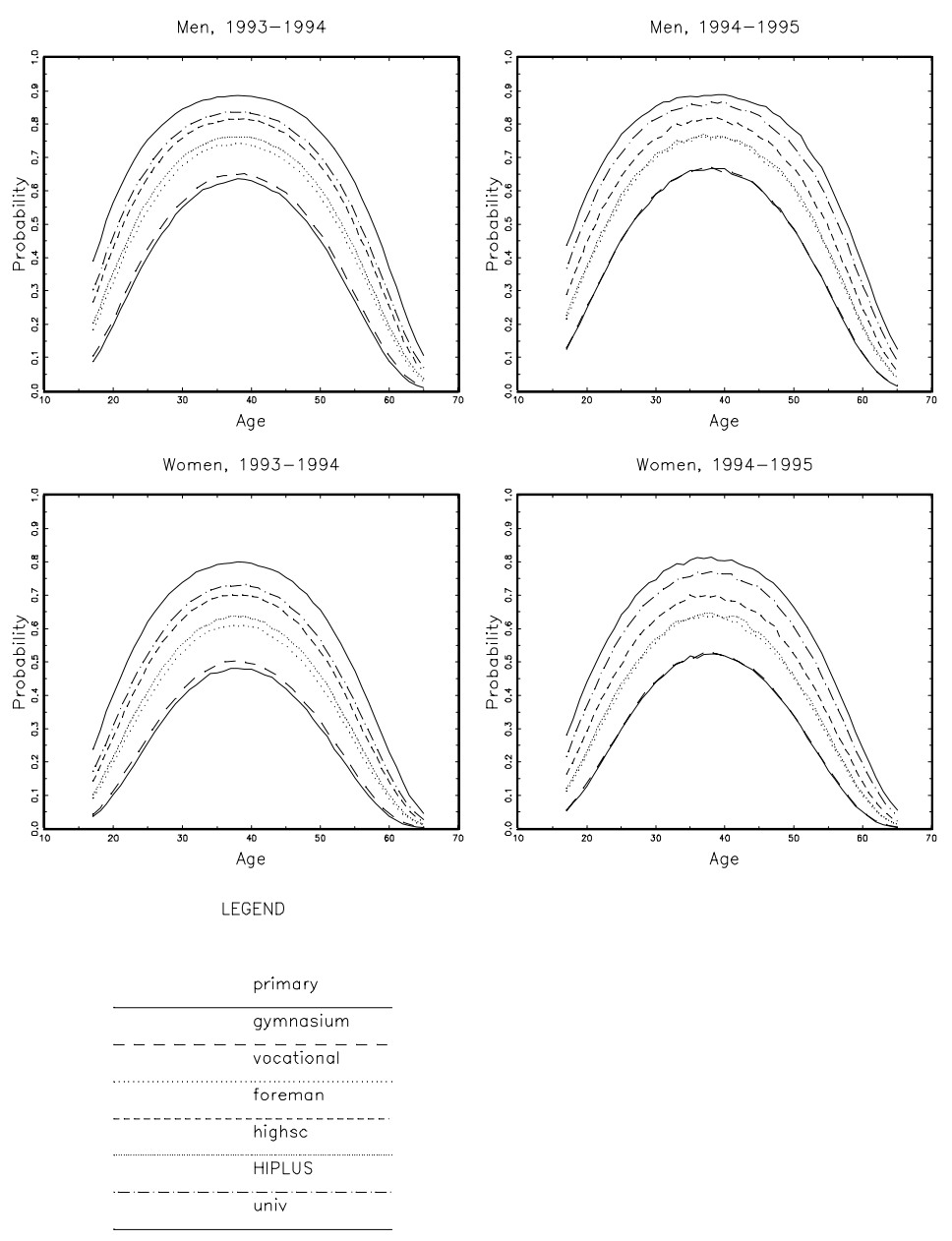
Figure 9: $P\left(N E_{t} \mid E_{t-1}\right)$, gender comparison
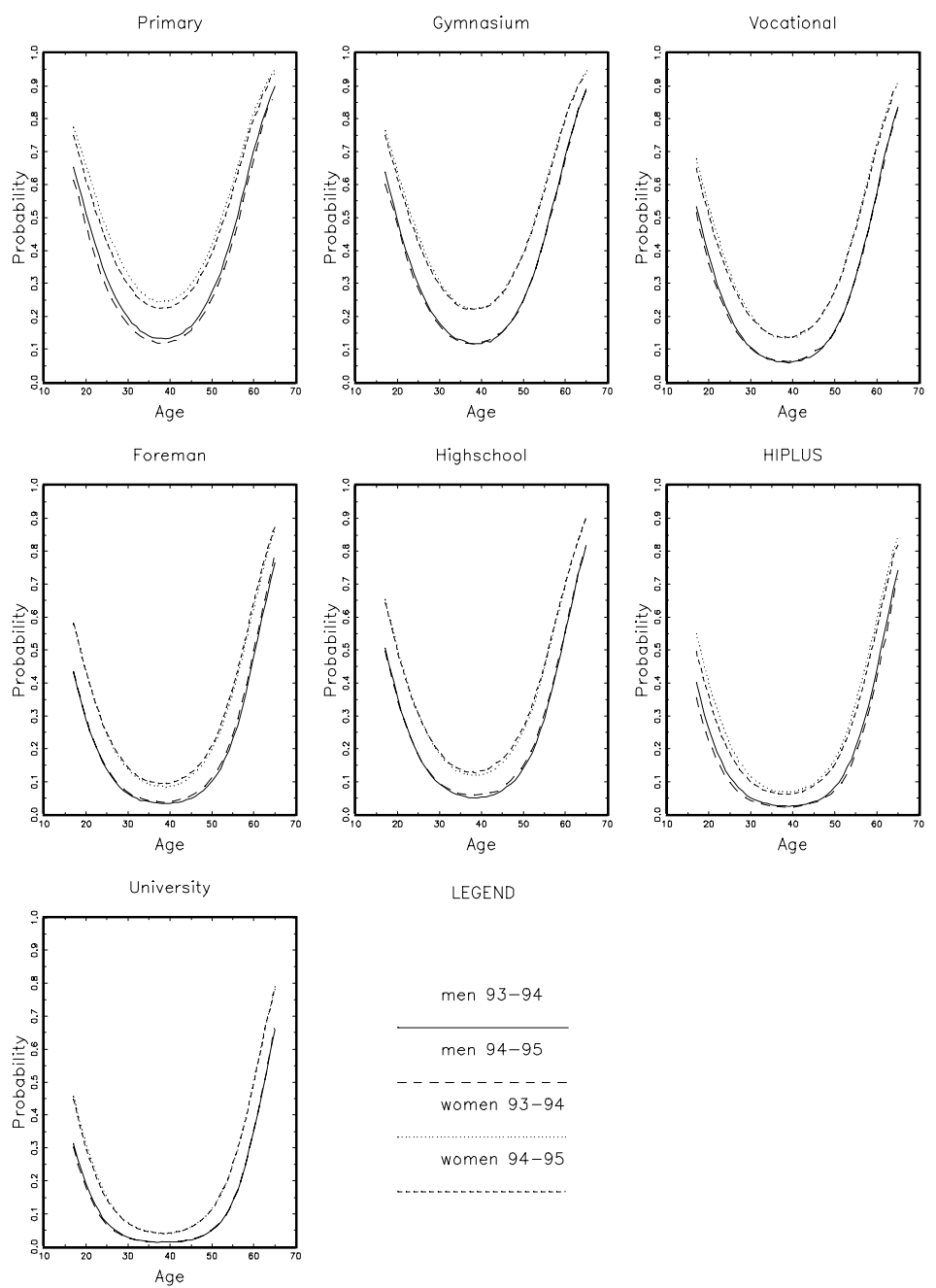

EGEND

$$
\begin{array}{r}
\text { men } 93-94 \\
\hline \text { men } 94-95 \\
\text { women } 93-94 \\
\text { women } 94-95 \\
\ldots
\end{array}
$$


Figure 10: $P\left(E_{t} \mid N E_{t-1}\right)$, gender comparison
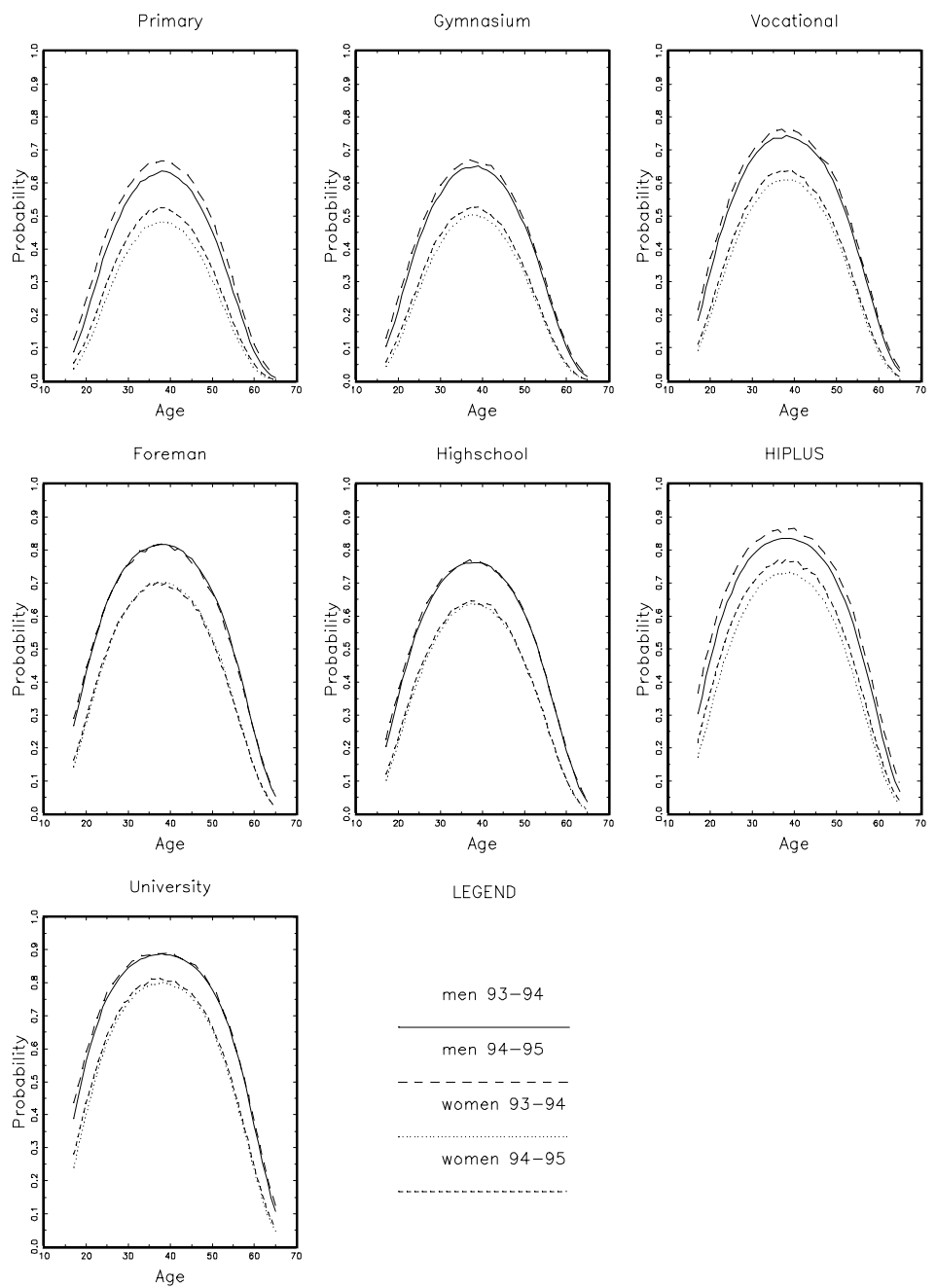

LEGEND

$$
\begin{gathered}
\text { men } 93-94 \\
\text { men } 94-95 \\
\text { women } 93-94 \\
\text { women } 94-95
\end{gathered}
$$


Figure 11: Probability of entire history (E-NE-E)
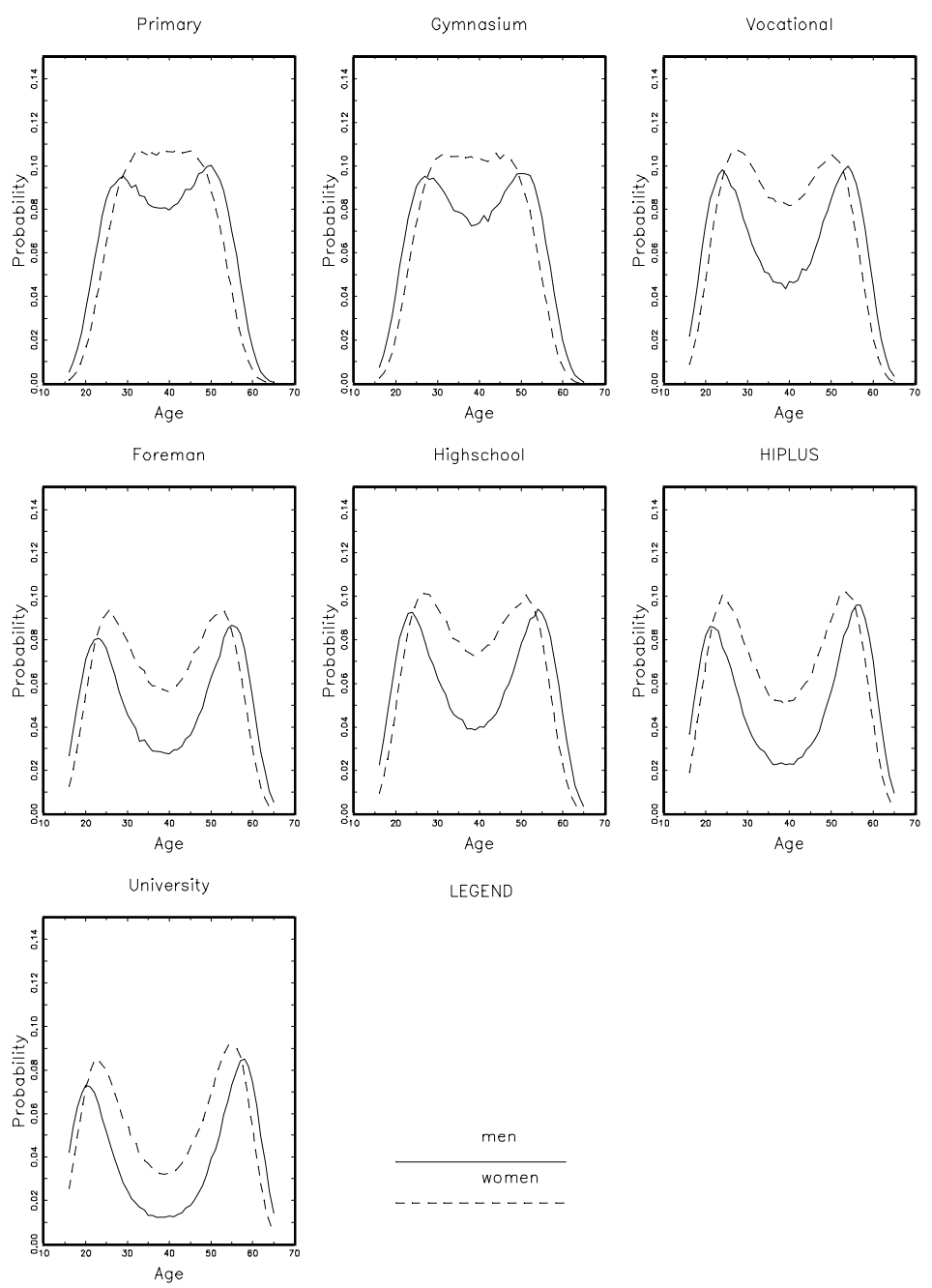

GEND

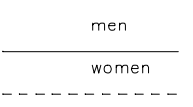


Figure 12: Marginal effect of past LF status

Primary

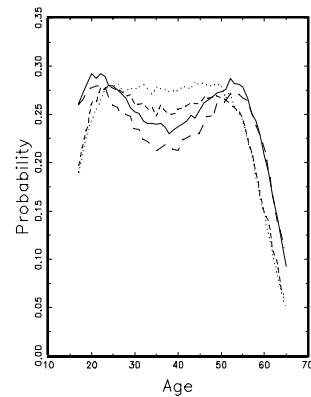

Foreman

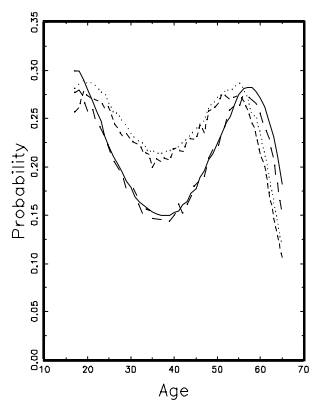

University

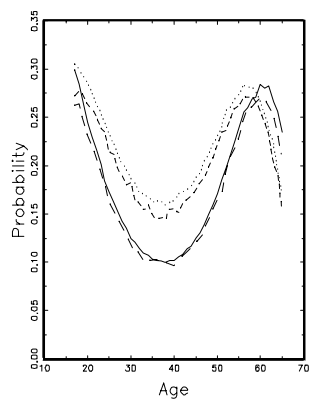

Gymnosium

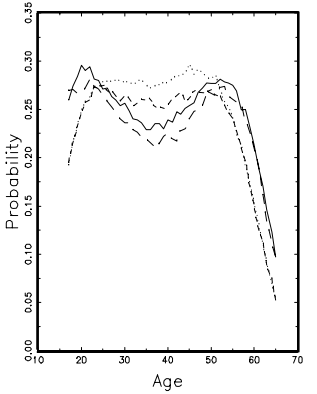

Highschool

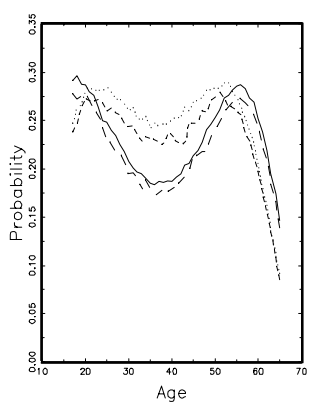

EGEND

men 93-94

men 94-95

women $93-94$

women 94-95
Vocational

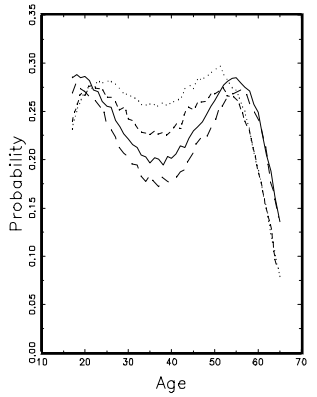

HIPLUS

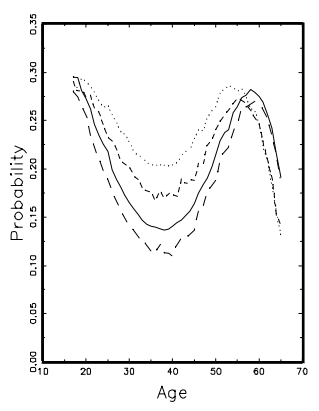

.......................... 


\section{IZA Discussion Papers}

\begin{tabular}{|c|c|c|c|c|}
\hline No. & Author(s) & Title & Area & Date \\
\hline 423 & $\begin{array}{l}\text { E. Feess } \\
\text { G. Muehlheusser }\end{array}$ & Transfer Fee Regulations in European Football & 1 & $02 / 02$ \\
\hline 424 & $\begin{array}{l}\text { F. Büchel } \\
\text { M. van Ham }\end{array}$ & $\begin{array}{l}\text { Overeducation, Regional Labour Markets and } \\
\text { Spatial Flexibility }\end{array}$ & 3 & $02 / 02$ \\
\hline 425 & F. Büchel & $\begin{array}{l}\text { Successful Apprenticeship-to-Work Transitions: } \\
\text { On the Long-Term Change in Significance of the } \\
\text { German School-Leaving Certificate }\end{array}$ & 3 & $02 / 02$ \\
\hline 426 & $\begin{array}{l}\text { J. Hartog } \\
\text { W. P. M. Vijverberg }\end{array}$ & $\begin{array}{l}\text { Do Wages Really Compensate for Risk Aversion } \\
\text { and Skewness Affection? }\end{array}$ & 5 & $02 / 02$ \\
\hline 427 & D. Del Boca & $\begin{array}{l}\text { The Effect of Child Care and Part Time } \\
\text { Opportunities on Participation and Fertility } \\
\text { Decisions in Italy }\end{array}$ & 6 & $02 / 02$ \\
\hline 428 & D. Del Boca & $\begin{array}{l}\text { Mothers, Fathers and Children after Divorce: } \\
\text { The Role of Institutions }\end{array}$ & 6 & $02 / 02$ \\
\hline 429 & $\begin{array}{l}\text { S. Anger } \\
\text { J. Schwarze }\end{array}$ & $\begin{array}{l}\text { Does Future PC Use Determine Our Wages } \\
\text { Today? Evidence from German Panel Data }\end{array}$ & 5 & $02 / 02$ \\
\hline 430 & $\begin{array}{l}\text { J. Schwarze } \\
\text { M. Härpfer }\end{array}$ & $\begin{array}{l}\text { Are People Inequality Averse, and Do They } \\
\text { Prefer Redistribution by the State? Evidence } \\
\text { From German Longitudinal Data on Life } \\
\text { Satisfaction }\end{array}$ & 3 & $02 / 02$ \\
\hline 431 & $\begin{array}{l}\text { M. Fertig } \\
\text { C. M. Schmidt }\end{array}$ & $\begin{array}{l}\text { The Perception of Foreigners and Jews in } \\
\text { Germany - A Structural Analysis of a Large } \\
\text { Opinion Survey }\end{array}$ & 6 & $02 / 02$ \\
\hline 432 & E. Tekin & $\begin{array}{l}\text { Employment, Wages, and Alcohol Consumption } \\
\text { in Russia: Evidence from Panel Data }\end{array}$ & 4 & $02 / 02$ \\
\hline 433 & $\begin{array}{l}\text { J. D. Angrist } \\
\text { A. D. Kugler }\end{array}$ & $\begin{array}{l}\text { Protective or Counter-Productive? Labor Market } \\
\text { Institutions and the Effect of Immigration on EU } \\
\text { Natives }\end{array}$ & 3 & $02 / 02$ \\
\hline 434 & A. D. Kugler & $\begin{array}{l}\text { From Severance Pay to Self-Insurance: Effects } \\
\text { of Severance Payments Savings Accounts in } \\
\text { Colombia }\end{array}$ & 4 & $02 / 02$ \\
\hline 435 & $\begin{array}{l}\text { G. S. Epstein } \\
\text { M. E. Ward }\end{array}$ & $\begin{array}{l}\text { Perceived Income, Promotion and Incentive } \\
\text { Effects }\end{array}$ & 1 & $02 / 02$ \\
\hline 436 & A. Kunze & $\begin{array}{l}\text { The Evolution of the Early Career Gender Wage } \\
\text { Gap }\end{array}$ & 1 & $02 / 02$ \\
\hline 437 & M. Fertig & $\begin{array}{l}\text { Evaluating Immigration Policy Potentials and } \\
\text { Limitations }\end{array}$ & 6 & $02 / 02$ \\
\hline 438 & A. Voicu & $\begin{array}{l}\text { Employment Dynamics in the Romanian Labor } \\
\text { Market: A Markov Chain Monte Carlo Approach }\end{array}$ & 4 & $02 / 02$ \\
\hline
\end{tabular}

An updated list of IZA Discussion Papers is available on the center's homepage www.iza.org. 